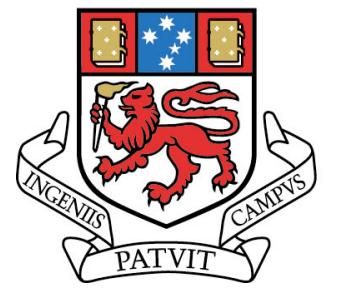

$$
\begin{aligned}
& \text { UNIVERSITY } \\
& \text { OFTASMANIA }
\end{aligned}
$$

Empirical Validation of a Model Predicting Depression, Anxiety, and Stress in the Parents of Children with Autism.

Scarlett Bones

A report submitted as a partial requirement for the degree of Bachelor of Psychology with Honours at the University of Tasmania.

2017

Division of Psychology, School of Medicine

University of Tasmania 


\section{Statement of Sources}

I declare that this report is my own original work and that contributions of others have been duly acknowledged.

\section{Ebonas}

Date: 19/10/2017

Scarlett Bones

October 2017. 


\section{Acknowledgments}

First and foremost I would like to thank my supervisor Dr. Kimberley Norris, for all her time, guidance, support, and understanding. Your dedication and enthusiasm when answering my never-ending list of questions was very much appreciated. Furthermore, your calmness and reassurance helped me overcome my frequent catastrophising. I would not be here without your extensive knowledge and constant support.

Secondly, I would like to thank Dr. Michael Quinn. I sincerely appreciate your assistance with my Honours project on top of your other demands. Your support and SEM and Mplus knowledge made my analysis and results substantially less anxiety provoking.

Thirdly, I would like to thank my family and friends, especially my parents who throughout the year have provided me with love, support, and food whenever required. I am also extremely grateful to have shared this experience with my fellow Honours students, specifically Ruby, Amy, and Ellie. I would not have made it through this year without your support and humour.

I would also like to thank the Autism groups and organisations who advertised on my behalf. Finally, I would like to thank the parents who participated in my study, especially those of children with ASD. I deeply appreciate you giving up your valuable time to participate in my study, and your support and parental experiences were a continual source of motivation for me throughout the year. 


\section{Table of Contents}

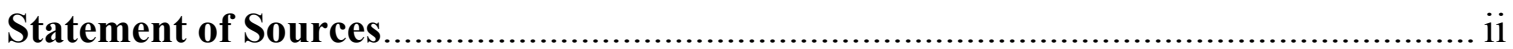

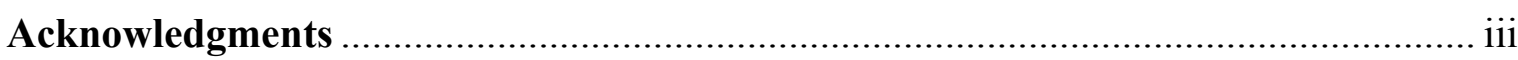

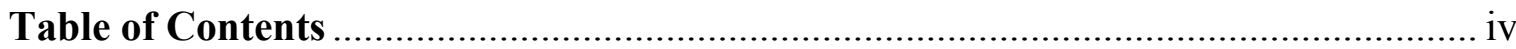

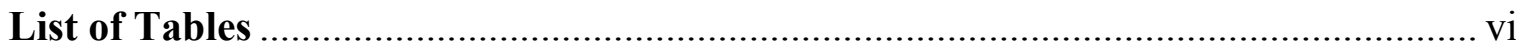

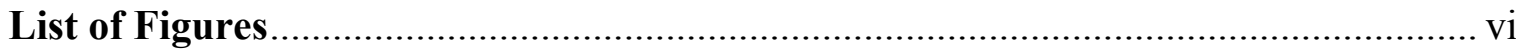

Abstract

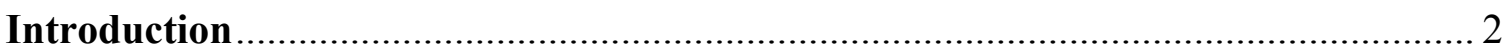

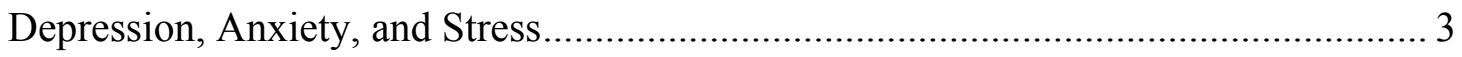

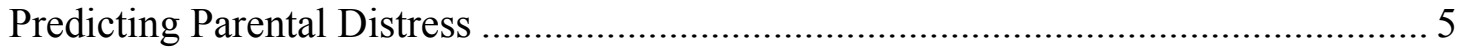

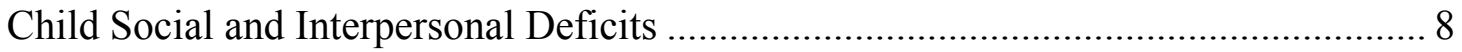

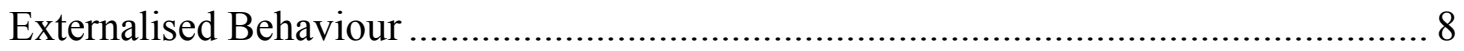

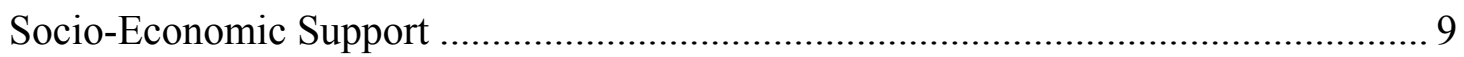

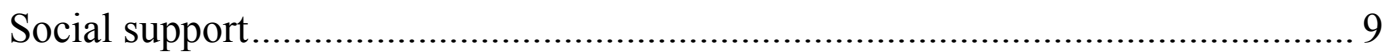

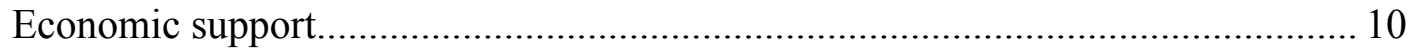

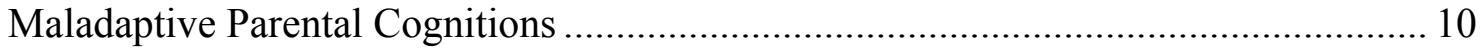

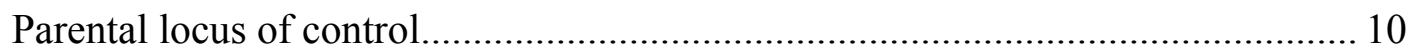

Perceived limit setting ability.................................................................... 11

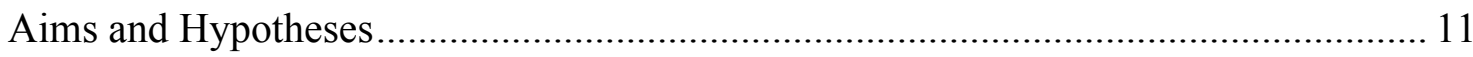

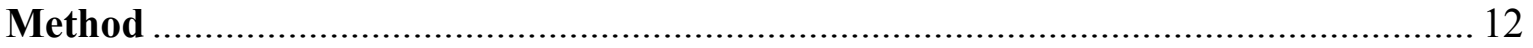

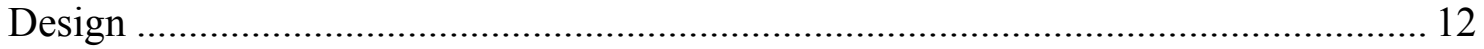

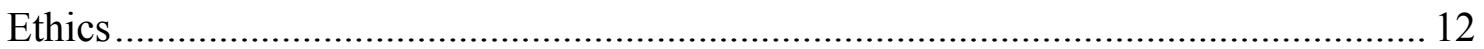

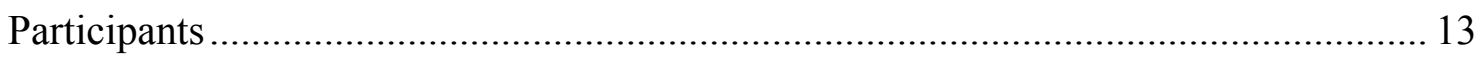

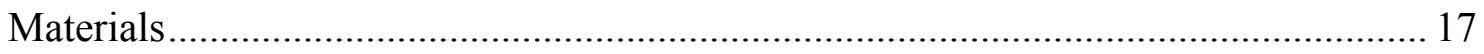

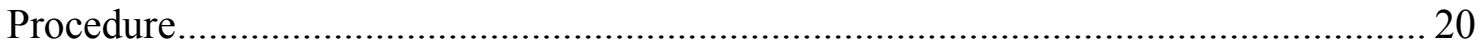


Data Analysis

Results 23

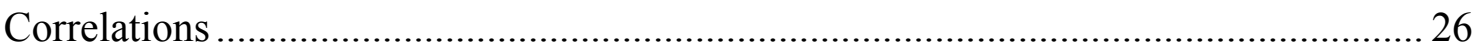

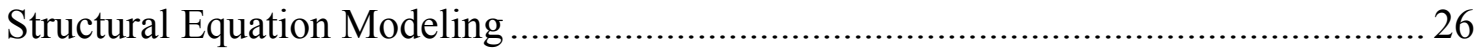

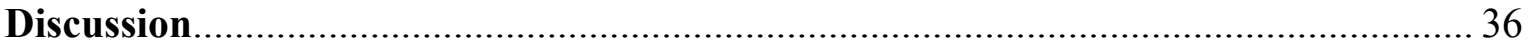

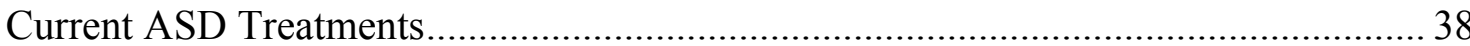

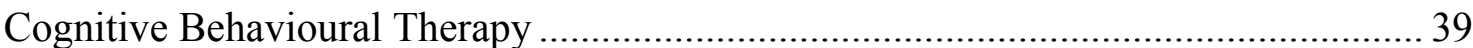

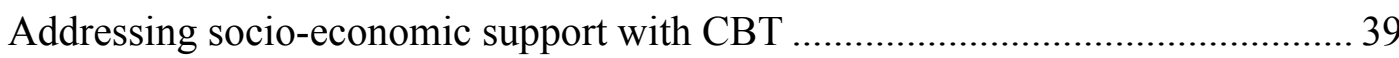

Addressing maladaptive parental cognitions with CBT ..................................... 41

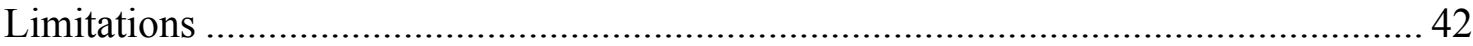

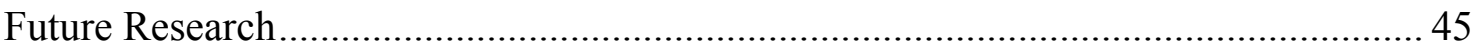

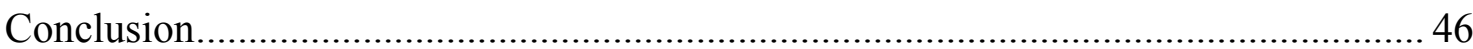

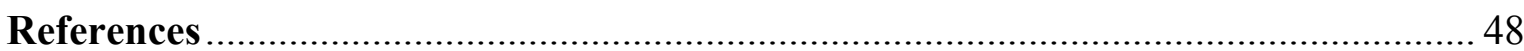

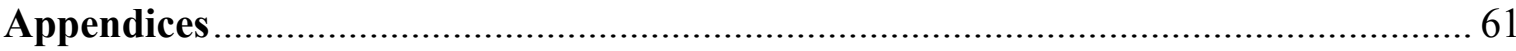

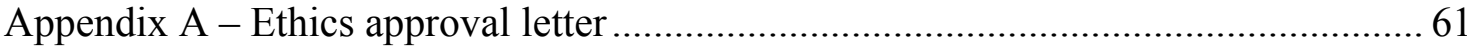

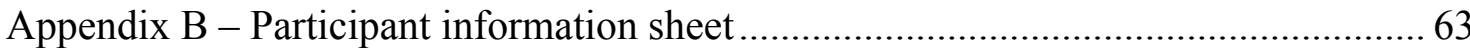

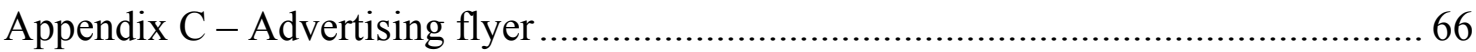

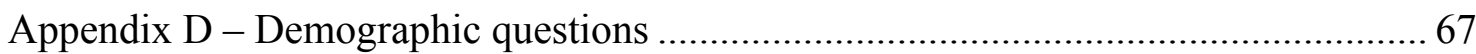

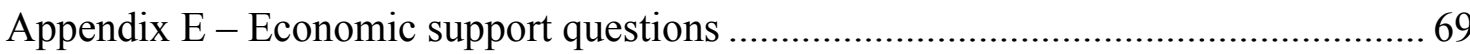

Appendix F - Summary of Intercorrelations between model indicators ...................... 70 


\section{List of Tables}

Table 1. Categorical Parent Demographic Variables ...................................................... 14

Table 2. Categorical Child Demographic Variables ...................................................... 16

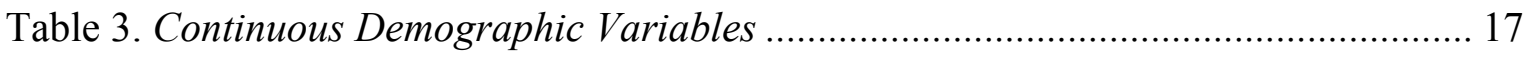

Table 4. Descriptives Statistics and Cronbach's Alpha Values in Whole Sample.............. 23

Table 5. Comparison of ASD and Non-ASD Samples on Study Indicators ....................... 25

Table 6. STDYX Factor Loadings for Model A in ASD Sample ........................................ 29

Table 7. STDYX Regression Coefficients for Model A in ASD Sample ............................. 31

Table 8. STDYX Factor Loadings for Model A in Whole Sample .................................... 34

Table 9. STDYX Regression Coefficients for Model A, in Whole Sample .......................... 35

\section{List of Figures}

Figure 1. Model A (Adapted Version) ...................................................................... 
Empirical Validation of a Model Predicting Depression, Anxiety, and Stress in the Parents of Children with Autism.

Scarlett Bones

Word count:

9,997 


\begin{abstract}
Distress in the parents of children with Autism Spectrum Disorder (ASD) can detrimentally impact parent and child function, making the prediction of distress in this parental group particularly important. Model A, developed by Falk et al. (2014) demonstrates that the relationship between child-centric variables (child social/interpersonal deficits and externalised behaviour) with parental distress is mediated by parent-centric variables (socioeconomic support and maladaptive parental cognitions). However, this model has not been validated in subsequent populations. The current study recruited 252 parents of children aged 4-17 years, with and without ASD. Participants completed an online questionnaire, containing measures of child social/interpersonal deficits, externalised behaviour, maladaptive parental cognitions and socio-economic support. Using SEM, the model was found to be a good fit for parents of children with ASD. The model was also a good fit for the whole sample, providing preliminary evidence of universality. These results support the finding that parent-centric, rather than child-centric, variables are the best predictors of distress. Furthermore, these results suggest that Model A may effectively predict parental distress in general. It is argued that parental distress should be considered a key target when treating ASD, and that interventions should focus on the parent as well as the child.
\end{abstract}


Autism Spectrum Disorder (ASD) is a developmental disorder characterised by impairments in social interactions and communication, restricted interests, and repetitive behaviour patterns (American Psychiatric Association [APA], 2013). Australian ASD prevalence rates are $.8 \%$ for males and .2\% for females (Australian Bureau of Statistics [ABS], 2012).

Researchers argue that ASD likely results from a combination of neurological, biochemical and genetic factors, and problems during pregnancy/birth (Happé \& Ronald, 2008; Happé, Ronald \& Plomin, 2006). There is no cure for ASD; however interventions can improve child function and help the family cope better (Harris, 1984; Myers \& Johnson, 2007). Behavioural interventions are the dominant treatment approach for ASD and include Applied Behavioural Analysis (ABA), social skills training, and cognitive behavioural therapy (Ospina et al., 2008). However, there is debate regarding which treatment is most effective (Ospina et al., 2008). As ASD is a complex disorder with many symptoms, treatment may be most effective when tailored to the needs of the child and family (Ospina et al., 2008).

Parents are often trained in how to implement behavioural interventions at home and parental involvement has been found to result in improved child outcomes, including reduced problem behaviour (Maughan, Christiansen, Jenson, Olympia, \& Clark, 2005). Parents are therefore integral to the management of their child's disorder. However, the challenges of raising a child with ASD can negatively impact upon parental mental health, making the implementation of interventions difficult, potentially resulting in reduced child functioning (Harris, 1984).

Parenting in general places large intellectual, emotional, and physical demands upon individuals (Coleman \& Karraker, 1997). However, raising a child with ASD has additional issues to those faced by parents of children with typical development. The diagnosis of ASD 
can be time-consuming and result in parental feelings of devastation, depression, denial, and confusion (Altiere \& Von Kluge, 2009). Altiere (2006) interviewed 52 parents of children with ASD and all parents reported the diagnosis to be a life-altering event, with some comparing it to the death of a family member. The behavioural problems associated with ASD (e.g., tantrums and obsessive behaviours) can also be challenging and stressful for parents (Holden \& Gray, 1992). Furthermore, many parents report a lack of understanding in society about the demands of raising a child with ASD, and experience stigmatisation (Meirsschaut, Roeyers \& Warreyn, 2010; Woodgate, Ateah \& Secco, 2008). Finally, as there is no cure for $\mathrm{ASD}$, parents have to come to terms with the long-term and challenging nature of their child's disorder, and how it will impact upon the rest of their lives (Holden \& Gray, 1992). These demands can negatively impact upon parental mental health, including depression, anxiety, and stress levels.

\section{Depression, Anxiety, and Stress}

Depression refers to a negative mood state characterised by low mood, negative affect, feelings of hopelessness and worthlessness, and a loss of interest and/or pleasure (Antony, Bieling, Cox, Enns \& Swinsom, 1998). Anxiety refers to a negative mood state characterised by panic, worry, and physiological arousal (e.g. increased heart and respiration rates) due to the anticipation of threat or danger (Bishop, 2007). Finally, stress refers to a state that occurs when an individual perceives that the demands upon them exceed their capacity to cope, resulting in tension, irritability, and a tendency to overreact to situations/events (Antony et al., 1998; Cohen, Kessler \& Gordon, 1995). In the current study, depression, anxiety, and stress are collectively termed distress.

Bitsika and Sharpley (2004) examined distress in 107 Australian parents of children with ASD and found that over $80 \%$ had moderate-severe anxiety scores, $60 \%$ had moderatesevere depression scores, and 70\% had high-very high parenting stress scores. Similarly, 
Davis and Carter (2008) and Hastings and Brown (2002) found that 20-50\% of parents of children with ASD had clinically significant levels of depression, anxiety, and/or stress.

These figures all exceed the anxiety and depression prevalence rates for the general Australian population (14\% and 6\% respectively; ABS, 2007), indicating that parents of children with ASD experience clinically significant levels of distress. Furthermore, researchers have found that parents of children with ASD experience significantly higher levels of distress than parents of children with typical development, Down syndrome, or mental retardation (Lee et al., 2009; McStay, Dissanayake, Scheeren, Koot, \& Begeer, 2013; Micali, Chakrabarti \& Fombonne, 2004).

Parents of children with ASD are therefore at high risk of distress, which can negatively impact upon their health and functioning. Depression, anxiety, and stress have been found to increase risk for health conditions such as heart disease and diabetes (Hollon, Thase \& Markowitz, 2002). Furthermore, distress can negatively impact upon parenting ability for several reasons. Firstly, highly distressed parents may have less patience or be less able to effectively respond to their child (Osborne \& Reed, 2009). Secondly, distress may lead to changes in appraisal, whereby highly distressed parents perceive child behaviours as more negative or threatening (Fong, 1991; Reed Howse, Ho \& Osborne, 2016). Thirdly, highly distressed parents may be less able to effectively implement treatment interventions (Osborne, McHugh, Saunders \& Reed, 2008).

Parental distress can also detrimentally impact child functioning. Osborne et al. (2008) found that parental stress counteracted the effectiveness of an ASD intervention, by reducing parents' ability to effectively implement the intervention. Increased parental stress can also exacerbate child behavioural problems (Lecavalier, Leone \& Wiltz, 2006), suggesting that parental distress is detrimental to both parent and child functioning. 
There is limited research examining the effect of parent-focused interventions on parent and child outcomes in relation to ASD. This is likely due to current interventions failing to address parental factors, instead primarily focusing on ASD psychoeducation and the implementation of child-focused behavioural techniques (Gavita, Joyce, \& David, 2011; Keen, Couzens, Muspratt \& Rodger, 2010). However, Gavita et al. (2011) and Osborne and Reed $(2009 ; 2010)$ argue that interventions addressing parental factors may result in the development of effective parenting behaviours, subsequently improving child outcomes.

Consistent with this, Gavita and Joyce's (2008) review of studies examining parental interventions in parents of children with externalised behaviour found that interventions containing parent-focused cognitive elements were more effective at reducing child disruptive behaviour and parental distress than interventions that did not contain such elements. Furthermore, these improvements were maintained at a three-year follow up, suggesting that targeting parental distress could improve both parent and child outcomes in the short and longer-term.

\section{Predicting Parental Distress}

The treatment of ASD has historically focused almost exclusively on the child (Gavita, et al., 2011; Keen et al., 2010). However, some researchers argue that a more holistic treatment approach may be beneficial, with support for both the child and parents (Falk, Norris \& Quinn, 2014). In order to develop effective parental interventions, there needs to be an understanding of the factors that predict distress. Such knowledge could also be used to evaluate existing ASD interventions to ensure they target factors that improve parent and child outcomes.

Previous researchers have suggested that ASD severity, externalised behaviour, and social support are significant predictors of distress in the parents of children with ASD (Falk et al., 2014). However, few researchers have examined the ability of multiple factors to 
predict depression, anxiety, and stress simultaneously, with most studies examining only one or two predictor and outcome variables (Falk et al., 2014). This is an issue as each variable may predict parental distress when analysed in isolation, but may not be significant when analysed in conjunction with other variables (Falk et al., 2014). The simultaneous analysis of several predictor and outcome variables more readily assesses the experiences of parents of children with ASD, as in the real world there are likely to be multiple contributing factors to distress and parents are likely to present with a mixture of symptoms (Falk, 2012).

This issue was addressed by Falk et al. (2014), who surveyed 250 mothers and 229 fathers of children with ASD to determine the best predictors of depression, anxiety, and stress (distress). Seventeen variables were analysed, including ASD severity, externalised behaviour, socio-economic support, and parental cognitions. Hierarchical stepwise regression revealed that ASD severity and externalised behaviour were significant predictors of parental distress. However, parent-centric variables (socio-economic support and parental cognitions) were better predictors in this regard. This is inconsistent with previous research, which indicated that child-centric variables, such as ASD severity and externalised behaviour, were the best predictors (Davis \& Carter, 2008; McStay et al., 2013).

Based on these results Falk et al. (2014) created a model (Model A), arguing that the relationship between ASD severity and externalised behaviours with parental distress is mediated by parental cognitions and socio-economic support. The terminology within this model has since been adapted for use in non-ASD samples (See Figure 1 for adapted model). 


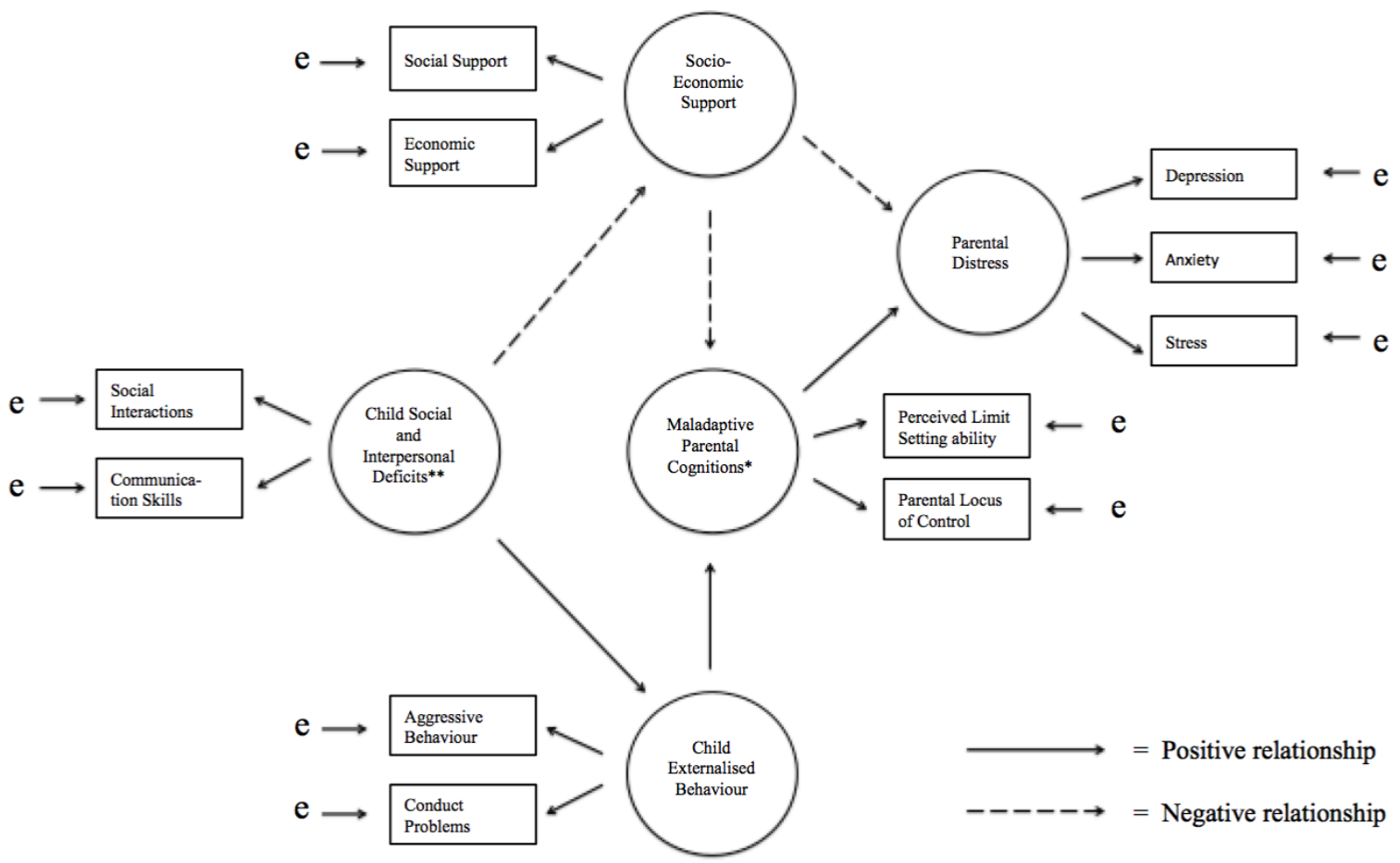

Figure 1. Model A. e = error variance. Circles represent latent variables (factors); rectangles represent observed variables (indicators). Solid lines represent positive relationships; broken lines represent negative relationships. * Parental Cognitions was altered to Maladaptive Parental Cognitions for ease of interpretation ** ASD Severity was altered to Child Social and Interpersonal Deficits to facilitate use in non-ASD samples. Adapted from "The Factors Predicting Stress, Anxiety, and Depression in the Parents of Children with Autism" by N. H. Falk, K. Norris, and M. G. Quinn, 2014, Journal of Autism and Developmental Disorders, 44, p. 3196. Copyright 2014 by N. Falk.

Falk et al. (2014) tested Model A using Structural Equation Modeling (SEM) and found that it was a good fit for the data for both mothers and fathers of children with ASD. However, further research is required to determine the clinical utility of the model as it is yet to be validated in a population beyond which it was originally developed. Validation would support the argument that parent-centric, rather than child-centric, factors are the best predictors of parental distress. Further research should also examine whether Model A is effective at predicting distress only in parents of children with ASD, or in other parental groups as well, in order to better understand whether distress in the parents of children with ASD is predicted by unique factors. The variables within Model A are discussed below. 


\section{Child Social and Interpersonal Deficits}

The severity of ASD varies along a continuum, whereby some individuals are severely affected and have notably impaired function (deficits in reciprocal social interactions, communication, and restricted/repetitive behaviours), while others are less affected and have fewer impairments in this regard (Pozo, Sarria, \& Brioso, 2011; Rutter, Bailey, \& Lord, 2003). Furthermore, children without ASD can have some ASD-type behaviours, including social and interpersonal deficits (Mulligan, Richardson, Anney, \& Gill, 2009). Pozo et al. (2011) argue that ASD severity is associated with parental distress, as children with more severe symptoms require more assistance and care, and are less autonomous than children with less severe symptoms (Pozo et al., 2011). Supporting this, ASD severity has been found to be associated with increased parental stress (Bebko et al., 1987; Hastings \& Johnson, 2001). However, not all parents of children with severe ASD experience clinically significant distress, suggesting that there are potential moderating or mediating variables at play (Pozo et al., 2011). Consistent with this argument, Falk et al. (2014) found that ASD severity was not the best predictor of parental distress, with externalised behaviour, socio-economic support and maladaptive parental cognitions mediating the relationship between ASD severity and distress.

\section{Externalised Behaviours}

Child externalised behaviours are those that are readily observable by others, and include aggression and conduct problems (e.g. fighting, stealing, disobedience; Donenberg \& Baker, 1993; Goodman, 2001). Behavioural problems tend to be antisocial and disruptive and have been rated by parents as the most challenging aspect of ASD (Bitsika \& Sharpley, 2004; Holden \& Gray, 1992). Furthermore, researchers have found that externalised behaviours, specifically conduct problems and aggression, are associated with increased parental stress 
(Gray, 2002; Lecavalier et al., 2006). However, Falk et al. (2014) found that externalised behaviours were not the best predictors of distress, with maladaptive parental cognitions mediating the relationship between externalised behaviour and distress.

\section{Socio-Economic Support}

\section{Social support.}

Social support is the provision of information or assistance that leads the recipient to feel cared for, loved, and/or valued (Cobb, 1976). Perceived social support is the amount of support that is perceived to be available by an individual, and is considered a more accurate measure of social support than objective measures such as the number of friends an individual has (Kawachi \& Berkman, 2001; Zimet, Dahlem, Zimet \& Farley, 1988).

Weiss (2002) found that mothers of children with ASD had significantly lower perceived social support than mothers of children with typical development or mental retardation. This disparity may be because the demands of raising a child with ASD are high, leaving little time for parents to spend with important others (Altiere, 2006). Furthermore, parents of children with ASD may experience the withdrawal of friends and family due to a lack of understanding regarding the demands of raising a child with ASD (Meirsschaut et al., 2010; Woodgate et al., 2008). Finally, parents may experience unhelpful cognitions, which alter perceptions of support (Brand, Lakey \& Berman, 1995).

Social support can buffer/reduce the effects of stress and increase the chances of successful adaptation by parents of children with ASD (Pozo et al., 2011; Seltzer, Krauss, Orsmond, \& Vestal, 2001). Previous research has found that high parental social support is associated with better psychological wellbeing and reduced depression and anxiety (Bromley, Hare, Davidson \& Emerson, 2004). In contrast, reduced social support can negatively influence parental mental health, potentially via impacts on cognitive appraisal, affect, and optimism (Ekas, Lickenbrock, \& Whitman, 2010). Furthermore, low social support has been 
found to be a significant predictor of parental distress (Bromley et al., 2004; Weiss, 2002).

\section{Economic support.}

Financial difficulties are common for parents of children with ASD. Two causes of financial difficulties are a reduction in household income due to parents reducing the number of working hours in order to care for their child (Meirsschaut et al., 2010); and secondly, potential out-of-pocket costs associated with diagnostic and treatment services (Altiere \& Von Kluge, 2009). This financial strain can result in increased distress.

Falk et al. (2014) found that socio-economic support had a direct negative effect on parental distress, as well as an indirect effect via parental cognitions. Furthermore, socioeconomic support mediated the relationship between ASD severity and parental distress.

\section{Maladaptive Parental Cognitions}

Growing evidence indicates that parent-centric variables, such as cognitions, may be better predictors of parental distress than child-centric variables (Falk et al., 2014).

Researchers have found that parents of children with ASD have lower perceived parenting confidence and competency than other parental groups (Bitsika \& Sharpley, 2004; Rodrigue, Morgan \& Geffken, 1990). Differences in cognitions between parental groups may help explain the high prevalence of distress in parents of children with ASD.

Two cognitions that have been examined in previous research are parental locus of control (LOC) and perceived limit setting ability. Both variables relate to a parent's ability to effectively control their child's behaviour, and are associated with parental distress (Falk, 2012).

\section{Parental locus of control.}

LOC refers to the degree to which people believe the outcome of an event is due to their own behaviour or due to external forces (Rotter, 1966). Parental LOC refers to the degree of control a parent perceives they have over their child's behaviour, as well as 
parental perceptions regarding the degree of control their child has over their life (Campis, Lyman, \& Prentice-Dunn, 1986). There is evidence that parents with a more internal LOC may see their child's development and behaviour as within their control, and therefore be motivated to implement strategies to address it (Hagekull, Bohlin \& Hammarberg, 2001). In contrast, a more external LOC may result in increased distress, as parents feel that their child's behaviour is out of their control.

Previous researchers have found that parental LOC is a significant predictor of parental stress in parents of children with an intellectual disability (Hassal, Rose \& McDonald, 2005). Furthermore, parental LOC was argued to potentially mediate the relationships between child maladaptive behaviour and social support with distress. Similarly, Falk et al. (2014) found that an external parental LOC was significantly associated with increased distress in both mothers and fathers of children with ASD. Furthermore, parental LOC mediated the relationships between externalised behaviour and socio-economic support with distress.

\section{Perceived limit setting ability.}

Perceived limit setting ability is a parent's perception of their ability to discipline and set limits for their child (Gerard, 1994). Higher perceived limit setting ability is considered a positive parenting skill, while lower levels are associated with increased stress (Osborne \& Reed, 2010). Consistent with this, Falk et al. (2014) found that lower limit setting ability was significantly associated with increased distress. Furthermore, perceived limit setting ability mediated the relationships between externalised behaviour and socio-economic support with distress.

\section{Aims and Hypotheses}

The current study aimed to validate Model A in a new sample and determine whether Model A demonstrated invariance for parents of children with and without ASD. Based on 
the findings by Falk et al. (2014) it was hypothesised that the model would be validated. No previous study has examined Model A in a non-ASD sample. However, as previous research has found significant differences between parents of children with and without ASD in levels of depression, anxiety, stress, and social support, it was hypothesised that the model would not demonstrate invariance (Seltzer et al., 2000; Weiss, 2002). It was therefore expected that Model A would only be effective at predicting distress in parents of children with ASD, and not in parents of children without ASD.

\section{Method}

\section{Design}

The current study was a cross-sectional correlational design. As shown earlier, Model A contains five latent variables (factors) and 11 observed variables (indicators); socioeconomic support (indicated by social and economic support), externalised behaviour (indicated by conduct problems and aggressive behaviour), child social and interpersonal deficits (indicated by communication skills and social interactions), maladaptive parental cognitions (indicated by perceived limit setting ability and parental LOC), and distress (indicated by depression, anxiety, and stress). The predictor/independent variables were child social and interpersonal deficits, externalised behaviour, socio-economic support, and maladaptive parental cognitions. The outcome/dependent variable was distress.

\section{Ethics}

Ethical approval was gained through the Tasmanian Social Sciences Human Research and Ethics Committee (Appendix A). A potential risk of the current study was increased distress from participants being asked about their mental health and their child's disorder and behaviour. Possible risks and benefits were outlined in the participant information sheet, thereby facilitating informed consent (Appendix B). Participants were able to withdraw at any point (prior to the submission of responses) without penalty. Participants also received 
the contact details of the researchers and relevant support services.

\section{Participants}

Participants comprised parents of children (aged 4 years 0 months to 17 years 11 months) with and without a diagnosis of ASD. Parental report was used to confirm ASD diagnosis. Parents of children without ASD were recruited to determine whether Model A would demonstrate invariance between parental groups, as previous research had not examined this.

The current study aimed to recruit at least 230 participants, in order to detect a moderate effect (.3) and achieve a power of .95 (G*power analysis). In total there were 379 respondents; 19 participants were excluded because they reported for children either younger or older than the age restriction of 4 to 17 years; 75 participants were excluded because they did not answer whether or not they had a child with ASD; and 33 participants were excluded because they did not provide data beyond demographic information. This resulted in a total sample size of 252 participants (138 parents of children with ASD; 114 parents of children without ASD). See Tables 1 and 2 for categorical demographic information about the parent and children respectively, and Table 3 for continuous demographic information. 
Table 1

Summary of Parent Categorical Demographic Variables

\begin{tabular}{|c|c|c|c|}
\hline Variable & Category & $N$ & $\%$ \\
\hline \multirow{3}{*}{$\begin{array}{l}\text { Are you the primary carer for } \\
\text { your child? }\end{array}$} & Yes & 239 & 66.4 \\
\hline & No & 20 & 5.6 \\
\hline & Not reported & 101 & 28.1 \\
\hline \multirow[t]{7}{*}{ Relationship with child } & Biological Mother & 218 & 60.6 \\
\hline & Biological Father & 27 & 7.5 \\
\hline & Step Mother/Foster Mother/Long- & 3 & .8 \\
\hline & Term Partner of Child's Father & & \\
\hline & $\begin{array}{l}\text { Step Father/Foster Father/Long } \\
\text { term Partner of Child's Mother }\end{array}$ & 11 & 3.1 \\
\hline & Other & 1 & .3 \\
\hline & Not reported & 100 & 27.8 \\
\hline \multirow[t]{3}{*}{ Parent Sex } & Female & 220 & 61.1 \\
\hline & Male & 38 & 10.6 \\
\hline & Not reported & 102 & 28.3 \\
\hline \multirow[t]{6}{*}{ Number of children with ASD } & 0 & 96 & 26.7 \\
\hline & 1 & 26 & 7.2 \\
\hline & 2 & 6 & 1.7 \\
\hline & 3 & 0 & 0 \\
\hline & 4 & 1 & .3 \\
\hline & Not responded & 231 & 64.2 \\
\hline \multirow[t]{4}{*}{ Education level } & High School/College & 95 & 26.4 \\
\hline & Tafe & 64 & 17.8 \\
\hline & Uni & 112 & 31.1 \\
\hline & Not reported & 89 & 24.7 \\
\hline \multirow[t]{5}{*}{ Marital status } & Married/Partner & 165 & 45.8 \\
\hline & Separated/Divorced & 36 & 10 \\
\hline & Widowed & 27 & 7.5 \\
\hline & Single & 43 & 11.9 \\
\hline & Not reported & 89 & 24.7 \\
\hline \multirow[t]{7}{*}{ Living arrangements } & Married living together & 89 & 24.7 \\
\hline & Married living apart & 2 & .6 \\
\hline & Defacto living together & 13 & 3.6 \\
\hline & Defacto living apart & 2 & .6 \\
\hline & Single & 30 & 8.3 \\
\hline & Other & 5 & 1.4 \\
\hline & Not reported & 219 & 60.8 \\
\hline \multirow[t]{4}{*}{ Employment Status } & Full-time & 48 & 113.3 \\
\hline & Part-time & 95 & 26.4 \\
\hline & Not employed & 128 & 35.6 \\
\hline & Not reported & 89 & 24.7 \\
\hline \multirow[t]{6}{*}{ Total annual income } & $\$ 0-19,999$ & 81 & 22.5 \\
\hline & $\$ 20-49,999$ & 107 & 29.7 \\
\hline & $\$ 50-79,999$ & 38 & 10.6 \\
\hline & $\$ 80+$ & 29 & 8.1 \\
\hline & NA & 16 & 4.4 \\
\hline & Not reported & 89 & 24.7 \\
\hline
\end{tabular}




\begin{tabular}{|c|c|c|c|}
\hline \multirow{7}{*}{$\begin{array}{l}\text { Total annual household } \\
\text { income }\end{array}$} & $\$ 0-19,999$ & 31 & 8.6 \\
\hline & $\$ 20-49,999$ & 80 & 22.2 \\
\hline & $\$ 50-79,999$ & 62 & 17.2 \\
\hline & $\$ 80-119,999$ & 54 & 15 \\
\hline & $\$ 120+$ & 38 & 10.6 \\
\hline & NA & 1 & .3 \\
\hline & Not reported & 94 & 26.1 \\
\hline \multirow[t]{3}{*}{ Parental Anxiety } & Yes & 131 & 36.4 \\
\hline & No & 145 & 40.3 \\
\hline & Not reported & 84 & 23.3 \\
\hline \multirow[t]{3}{*}{ Parental Depression } & Yes & 147 & 40.8 \\
\hline & No & 129 & 35.8 \\
\hline & Not reported & 84 & 23.3 \\
\hline \multirow[t]{3}{*}{ Parental Bipolar } & Yes & 13 & 3.6 \\
\hline & No & 263 & 73.1 \\
\hline & Not reported & 84 & 23.3 \\
\hline \multirow[t]{3}{*}{ Parental Anorexia } & Yes & 4 & 1.1 \\
\hline & No & 272 & 75.6 \\
\hline & Not reported & 84 & 23.3 \\
\hline \multirow[t]{3}{*}{ Parental Bulimia } & Yes & 3 & .8 \\
\hline & No & 273 & 75.8 \\
\hline & Not reported & 84 & 23.3 \\
\hline \multirow[t]{3}{*}{ Parental Schizophrenia } & Yes & 0 & 0 \\
\hline & No & 276 & 76.7 \\
\hline & Not reported & 84 & 23.3 \\
\hline \multirow[t]{3}{*}{ Parental Social Phobia } & Yes & 8 & 2.2 \\
\hline & No & 268 & 74.4 \\
\hline & Not reported & 84 & 23.3 \\
\hline \multirow[t]{3}{*}{ Parental ASD/Asperger's } & Yes & 11 & 3.1 \\
\hline & No & 265 & 73.6 \\
\hline & Not reported & 84 & 23.3 \\
\hline \multirow[t]{3}{*}{ Current medical condition } & Yes & 103 & 28.3 \\
\hline & No & 161 & 44.7 \\
\hline & Not reported. & 96 & 26.7 \\
\hline
\end{tabular}


Table 2

Summary of Child Categorical Demographic Variables

\begin{tabular}{|c|c|c|c|}
\hline Variable & Category & $N$ & $\%$ \\
\hline \multirow{3}{*}{ Child Sex } & Female & 97 & 26.9 \\
\hline & Male & 165 & 45.8 \\
\hline & Not reported & 98 & 27.2 \\
\hline \multirow{5}{*}{ Birth order } & Youngest & 71 & 19.7 \\
\hline & Middle & 29 & 8.1 \\
\hline & Eldest & 109 & 30.3 \\
\hline & Only & 53 & 14.7 \\
\hline & Not reported & 98 & 27.2 \\
\hline \multirow[t]{5}{*}{ Type of schooling } & Mainstream school & 102 & 28.3 \\
\hline & Special needs day school & 14 & 3.9 \\
\hline & Special needs boarding school & 1 & .3 \\
\hline & Full-time home care & 4 & 1.1 \\
\hline & Not reported & 239 & 66.4 \\
\hline \multirow[t]{3}{*}{ Child ADHD } & Yes & 59 & 16.4 \\
\hline & No & 216 & 60 \\
\hline & Not reported & 85 & 23.6 \\
\hline \multirow[t]{3}{*}{ Child ODD } & Yes & 22 & 6.1 \\
\hline & No & 253 & 70.3 \\
\hline & Not reported & 85 & 23.6 \\
\hline \multirow[t]{3}{*}{ Child Anxiety } & Yes & 86 & 23.9 \\
\hline & No & 189 & 52.5 \\
\hline & Not reported & 85 & 23.6 \\
\hline \multirow[t]{3}{*}{ Child Depression } & Yes & 29 & 8.1 \\
\hline & No & 246 & 68.3 \\
\hline & Not reported & 85 & 23.6 \\
\hline \multirow[t]{3}{*}{ Child Bipolar } & Yes & 2 & .6 \\
\hline & No & 273 & 75.8 \\
\hline & Not reported & 85 & 23.6 \\
\hline \multirow[t]{3}{*}{ Child Learning Disorder } & Yes & 2 & .6 \\
\hline & No & 236 & 65.6 \\
\hline & Not reported & 85 & 23.6 \\
\hline \multirow[t]{3}{*}{ Child Intellectual Disability } & Yes & 39 & 10.8 \\
\hline & No & 124 & 34.4 \\
\hline & Not reported & 230 & 63.9 \\
\hline \multirow[t]{3}{*}{ Child Conduct Disorder } & Yes & 3 & .8 \\
\hline & No & 272 & 75.6 \\
\hline & Not reported & 85 & 23.6 \\
\hline \multirow[t]{3}{*}{ Child Anorexia } & Yes & 1 & .3 \\
\hline & No & 274 & 76.1 \\
\hline & Not reported & 85 & 23.6 \\
\hline \multirow[t]{3}{*}{ Child Bulimia } & Yes & 3 & .8 \\
\hline & No & 273 & 75.8 \\
\hline & Not reported & 85 & 23.6 \\
\hline \multirow[t]{3}{*}{ Child Schizophrenia } & Yes & 1 & .3 \\
\hline & No & 274 & 76.4 \\
\hline & Not reported & 85 & 23.6 \\
\hline Child Asperger's & Yes & 39 & 10.8 \\
\hline
\end{tabular}




$\begin{array}{lll}\text { No } & 106 & 29.4 \\ \text { Not reported } & 215 & 59.7\end{array}$

Note. ADHD: Attention Deficit Hyperactivity Disorder; ODD: Oppositional Defiant Disorder

Table 3

Summary of Continuous Demographic Variables

\begin{tabular}{lll}
\hline Variable & $M$ & $S D$ \\
\hline Child age (years) & 9.57 & 3.84 \\
Parent age (years) & 38.97 & 8.84 \\
Number of people living in household & 3.99 & 1.32 \\
Number of children living in household & 2.06 & 1.07 \\
\hline
\end{tabular}

Participants were recruited through advertisements on a range of ASD support

Facebook groups. Participants were also recruited through flyers and lecture presentations at the University of Tasmania and newsletters at Tasmanian schools (Appendix C).

\section{Materials}

All measures were the same as those used by Falk et al. (2014), with the exception of the social support, and parental LOC measures. Cronbach's alpha values for all measures are presented in the results section. The questionnaire battery comprised the following scales:

Demographic information was gathered through a series of questions developed by the investigator. These questions were in two groups: questions about the parent (Table D1) and questions about the child (Table D2; Appendix D).

The short form Depression, Anxiety, and Stress Scale (DASS-21; Lovibond \& Lovibond, 1995) was used to measure the dependent variables. The DASS-21 contains three 7-item subscales (depression, anxiety, and stress; Lovibond \& Lovibond, 1995). Each item is in the form of a statement, and participants indicate the extent to which each item applied to themselves over the past week on a 4-point Likert scale ranging from 0 (Did not apply to me at all [never]) to 3 (Applied to me very much, or most of the time [almost always]; Lovibond \& Lovibond, 1995). Subscale scores range from 0-21, with higher scores indicating increased severity of symptoms (Lovibond \& Lovibond, 1995). The DASS-21 has good internal 
consistency with Cronbach's alpha values of $.81, .73$ and .81 for the depression, anxiety and stress scales respectively (Lovibond \& Lovibond, 1995).

The Berlin Social Support Scale (BSSS; Schwarzer \& Schulz, 2000) was used to assess social support. This scale was chosen as it is psychometrically validated, and therefore provides a more accurate measure of social support than the measure used by Falk et al. (2014). The BSSS contains 52 items on a four-point Likert scale ranging from 1 (strongly disagree) to 4 (strongly agree). The items are in the form of statements, and participants rate their level of agreement on each. The BSSS contains 6 subscales, the perceived support (8 items) subscale was used in the current study. Possible scores ranged from 8 to 32, with higher scores indicating higher levels of perceived social support. The BSSS has acceptable internal consistency, with Cronbach's alpha values for the subscales ranging from .63 to.83 (Schwarzer \& Schulz, 2000).

Economic support was measured with two items developed by Falk et al. (2014; Appendix E). These items were on a five-point Likert scale ranging from 1 (strongly disagree) to 5 (strongly agree). Possible scores ranged from 2-10, with higher scores indicating higher levels of perceived economic support. This measure has acceptable internal consistency, with a Cronbach's alpha value of .84 (Falk et al., 2014).

The Social Communication Questionnaire (SCQ; Rutter et al., 2003) was used to measure child social and interpersonal deficits. The SCQ contains 40 items that assess symptoms associated with ASD (Rutter et al., 2003). The SCQ has three domains, which correspond to the criteria within the Diagnostic and Statistical Manual $5^{\text {th }}$ edition for ASD (APA, 2013; Eaves, Wingert, Ho, \& Mickelson, 2006); reciprocal social interactions (15 items); communication skills (13 items); and restricted, repetitive and stereotyped behaviour patterns ( 8 items; Rutter et al., 2003). The social interactions and communication skills subscales were used in the current study. The items are administered in a yes/no response 
format. A score of 1 (yes response) indicates the presence of abnormal behaviour, and a score of 0 (no response) indicates the absence of abnormal behaviour. Higher scores indicate higher levels of abnormal behaviour (Rutter et al., 2003). Possible scores ranged from 0-15 for social interactions and 0-13 for communication skills. Previous research has found acceptable internal consistency, with Cronbach's alpha values of .84 to .93 (Rutter et al., 2003).

The Strengths and Difficulties Questionnaire (SDQ; Goodman, 1997) was used to assess child-externalised behaviour. The SDQ contains 25 items on a 3-point Likert scale, ranging from 0 (not true) to 2 (certainly true). There are five subscales, each with five questions. The conduct problems subscale was used in the current study. Possible scores ranged from 0-10, with higher scores indicating higher levels of conduct problems (Goodman, 1997). One question was altered from 'Steals from home, school or elsewhere' to 'Takes things without permission from home, school, or elsewhere'. This amendment was made in order to include circumstances where the child may not be aware that taking things without permission would be considered stealing. Furthermore, this change may increase accuracy of reporting by parents, as they also may not consider their child's behaviour to be stealing. This amendment was also made by Falk et al. (2014) for the same reasons. Previous research has found acceptable internal consistency, with a Cronbach's alpha value of .63 for the conduct problems subscale (Goodman, 2001).

Aggressive behaviour was measured with 1 item developed by Falk et al. (2014). The item was 'Often aggressive or violent towards adults'. Responses were on a 3-point likert scale ranging from 0 (not true) to 2 (certainly true). Possible scores ranged from 0-2, with higher scores indicating higher levels of aggressive behaviour.

The Parent-Child Relationship Inventory (PCRI; Gerard, 1994) was used to assess parental cognitions. The PCRI contains 78 items on a 4-point Likert scale ranging from 1 (strongly agree) to 4 (strongly disagree) and measures parent's perceptions about their 
relationship with their child (Gerard, 1994). The PCRI contains seven content scales. The perceived limit setting ability subscale (12 items) was used in the current study. Possible scores ranged from 12-48, with higher scores indicating lower levels of limit setting ability (Gerard, 1994). Previous research has found acceptable internal consistency, with Cronbach's alpha values above .70 for all subscales (Gerard, 1994).

A short form of the Parental Locus of Control Scale (PLOC; Campis et al., 1986) was used to assess parental LOC. The PLOC Short-Form (PLOC-SF) contains 25-items on a 5point Likert scale ranging from 1 (strongly disagree) to 5 (strongly agree). There are 4 dimensions of the PLOC-SF: parental efficacy, parental responsibility, child control of parent's life, and parental control of child's behaviour (Campis et al., 1986). Possible scores ranged from 25-125, with higher scores indicating a more external locus of control (Campis et al., 1986). Previous research has found good internal consistency for the PLOC, with a Cronbach's alpha value of .92 (Campis et al., 1986).

\section{Procedure}

Participants followed the link from advertisements to access the survey. Participants were shown the information sheet (Appendix B) detailing the purpose, method, possible risks and benefits, the voluntary nature of participation, their right to withdraw, data confidentiality, and relevant contact details. Once participants had read the information sheet they were able to commence the questionnaire, which contained the measures outlined above. Participants with more than one child were asked to answer all child-related questions based on only one of their children and to report on the same child for all sections. All questions were non-compulsory. Consent was implied through the submission of the survey and this was outlined in the information sheet. Upon submission participants were thanked for their participation and had the option of entering the draw to win one of four $\$ 50$ Coles-Myer vouchers, or Amazon vouchers if participants were outside Australia. First-year psychology 
students at the University of Tasmania were eligible for 1 hour's research credit for their participation.

\section{Data Analysis}

Data was analysed using Mplus version 7 (Muthén \& Muthén, 2012). SEM was conducted, using the Maximum Likelihood (ML) estimation procedure to determine whether the model was a good fit for the data and whether the model demonstrated invariance for parents of children with and without ASD. The $\chi^{2}$ likelihood ratio was used to indicate model fit, with a lower and non-significant value indicating a better fit. However, Brown (2006) recommends that $\chi^{2}$ not be used as the sole indicator, as it is almost always significant with large sample sizes. The Comparative Fit Index (CFI), Tucker-Lewis Index (TLI), Root Mean Square Error of Approximation (RMSEA), and Standard Root Mean square Residual (SRMR) were therefore also used to quantify the degree of fit (Hu \& Bentler, 1999).

CFI (Bentler, 1990) and TLI (Tucker \& Lewis, 1973) are incremental fit indices, meaning they evaluate fit by comparing the model to a more restricted, baseline model (Brown, 2006; Hu \& Bentler, 1999). CFI values range from 0-1, with greater values indicating better fit (Brown, 2006). Greater TLI values also indicate better fit, however, values can be greater than 1 (Brown, 2006). TLI also penalises complex models that do not significantly improve fit (Brown, 2006). CFI and TLI values of at least .90, preferably .95 or above, indicate good fit (Hooper, Coughlan \& Mullen, 2008; Hu \& Bentler, 1999).

RMSEA and SRMR are both referred to as absolute fit indices, meaning they evaluate how well a model reproduces the observed data, and do not use a reference model for comparison (Brown, 2006). RMSEA also includes a penalty for complex models (Brown, 2006). Lower values indicate better fit, with RMSEA values of less than .08 indicating moderate fit, and values less than .06 indicating good fit (Hu \& Bentler, 1999). The 90\% Confidence Interval (CI) indicates the precision of the RMSEA estimate, however, complex 
models usually result in wider CIs (Brown, 2006). SRMR values range from 0-1, with lower values indicating better fit (Brown, 2006). SRMR values of .08 or less indicate good fit (Hu \& Bentler, 1999).

Missing data were computed using pro-ration, rather than excluded. Missing data was likely due to the length of the questionnaire and the non-compulsory nature of questions. Excluding all participants may have therefore resulted in a substantial reduction in the sample size, and power of the analysis, as SEM requires sample sizes of 200 - 300 (Blunch, 2013; Van Ginkel, Sijtsma, Van der Ark, \& Vermunt, 2010). Furthermore, excluding missing data can result in biased results, as participants who do not respond to all items may differ from participants who do respond (Van Ginkel, et al., 2010). For example, parents in the current study who did not complete all items may have had less time available, been more distressed, or had children with more severe ASD. It was therefore decided that replacement of missing data was more appropriate.

Pro-ration involves replacing missing values with the mean of the other variables/items in that scale (Mazza, Enders \& Ruehlman, 2015). Pro-ration is a common technique to deal with missing data, and has been found to be appropriate when the number of missing items is less than 20\% (Downey \& King, 1998; Mazza et al., 2015). Pro-ration has been used to replace missing values in previous studies examining depression and anxiety (Forand \& DeRubeis, 2014; Hazel, Oppenheimer, Technow, Young \& Hankin, 2014). Furthermore, pro-ration has been found to be an appropriate technique to obtain index scores for the Weschler Adult Intelligence Scale (Olivier et al., 2013; Umfleet, Ryan, Gontkovsky \& Morris, 2012). As the current study is examining a clinical question, in a clinical population, pro-ration was deemed suitable. Furthermore, due to time constraints and the scope of this thesis it was considered appropriate. 


\section{Results}

Descriptive statistics and Cronbach's alpha values for all indicators in the whole sample are presented in Table 4.

Table 4

Means, Standard Deviations and Cronbach's Alphas for Model Indicators in Whole Sample

\begin{tabular}{lccc}
\hline Variable & $M$ & $S D$ & $\alpha$ \\
\hline Depression & 5.91 & 5.26 & .94 \\
Anxiety & 4.62 & 4.63 & .88 \\
Stress & 8.64 & 4.95 & .90 \\
Social Support & 25.96 & 5.22 & .92 \\
Economic Support & 6.15 & 2.51 & .79 \\
Social Interactions & 4.12 & 3.59 & .82 \\
Communication Skills & 4.82 & 2.66 & .66 \\
Conduct Problems & 3.19 & 2.58 & .78 \\
Aggressive Behaviour & .40 & .62 & - $^{\mathrm{a}}$ \\
Limit Setting Ability & 31.11 & 3.51 & .38 \\
Parental Locus of Control & 69.65 & 12.99 & .88 \\
\hline
\end{tabular}

Note. $\alpha=$ Cronbach's alpha.

${ }^{a}$ No Cronbach's alpha value for aggressive behaviour as single-item measure.

The Cronbach's alpha value for perceived limit setting ability was .38, indicating an issue with internal consistency (Bland \& Altman, 1997). However, as perceived limit setting ability is an indicator in the model this variable was still included in the analysis. 
Furthermore, previous research has shown acceptable internal consistency for this measure (Gerard, 1994). However, caution must be taken with the interpretation of results.

Depression, anxiety and stress scores were in the moderate range for parents of children with ASD and the normal range for parents of children without ASD (Lovibond \& Lovibond, 1995). This was expected, as previous research has shown that parents of children with ASD have higher levels of depression, anxiety, and stress than parents of children without ASD (Lee et al., 2009; McStay et al., 2013). Parents of children with ASD also scored higher on measures of child social and interpersonal deficits, externalised behaviour, and maladaptive parental cognitions and lower on measures of socio-economic support. Descriptive statistics for parents of children with and without ASD are presented in Table 5. 
Table 5

Comparison of Parents of Children With and Without ASD on Model Indicators

\begin{tabular}{|c|c|c|c|c|c|c|}
\hline \multirow[b]{3}{*}{ Variable } & \multirow{2}{*}{\multicolumn{2}{|c|}{$\begin{array}{l}\text { Parents of children } \\
\text { with ASD }\end{array}$}} & \multirow{2}{*}{\multicolumn{2}{|c|}{$\begin{array}{l}\text { Parents of children } \\
\text { without ASD }\end{array}$}} & \multirow[b]{3}{*}{$t$} & \multirow[b]{3}{*}{$d$} \\
\hline & & & & & & \\
\hline & $M$ & $S D$ & $M$ & $S D$ & & \\
\hline Depression & 7.66 & 5.59 & 3.80 & 3.90 & $6.23 * *$ & .79 \\
\hline Anxiety & 6.09 & 5.15 & 2.83 & 3.06 & $5.95 * *$ & .75 \\
\hline Stress & 10.51 & 4.88 & 6.37 & 4.00 & $7.26^{* *}$ & .92 \\
\hline Social Support & 24.12 & 5.21 & 28.24 & 3.72 & $7.08 * *$ & .90 \\
\hline Economic Support & 5.40 & 2.49 & 7.04 & 2.22 & $5.46^{* *}$ & .53 \\
\hline Social Interactions & 6.23 & 3.19 & 1.34 & 1.63 & $14.84 * *$ & 1.88 \\
\hline Communication Skills & 6.05 & 2.32 & 3.16 & 2.10 & $10.27 * *$ & 1.30 \\
\hline Conduct Problems & 4.07 & 2.61 & 2.12 & 2.11 & $6.43 * *$ & .81 \\
\hline Aggressive Behaviour & .59 & .69 & .15 & .41 & $5.99 * *$ & .76 \\
\hline Limit Setting Ability & 32.83 & 2.90 & 28.97 & 2.98 & $10.39 * *$ & 1.31 \\
\hline Parental Locus Of & 75.52 & 10.31 & 62.34 & 12.20 & $9.29 * *$ & 1.18 \\
\hline Control & & & & & & \\
\hline
\end{tabular}

Note. $d=$ Cohen's d effect size.

$* *=p<.001$.

Bonferroni adjusted $(\alpha=.004)$ independent samples $t$-tests were conducted comparing parents of children with and without ASD on each indicator. $T$-test results and Cohen's $d$ effect sizes are presented in Table 5. It was found that there was a significant difference between parents of children with and without ASD on all indicators, with moderate to large effect sizes. Parents of children with ASD had significantly higher levels of distress 
(depression, anxiety and stress), maladaptive parental cognitions (parental LOC and perceived limit setting ability), child social and interpersonal deficits (communication skills and social interactions), and externalised behaviour (conduct problems and aggressive behaviour), and significantly lower levels of socio-economic support (social and economic support). These analyses acted as a validity check, confirming that in the current sample, parents of children with ASD significantly differed from parents of children without ASD.

\section{Correlations}

The indicators were then correlated to determine any issues with collinearity. See Appendix F for correlation coefficients. Correlations between depression, anxiety, and stress were between .64 and .77 . However, this was expected, due to the high factor correlations of the DASS (Lovibond \& Lovibond, 1995). The correlation between social interactions and communication skills was also high, at .69. However, this was also expected due to the high factor correlations of the SCQ (Rutter et al., 2003). Correlation coefficients above .60 were also found between conduct problems and aggressive behaviour (.66), and limit setting ability and parental LOC (.64). However, no correlations were above .80. All VIF values were less than 10 and all Tolerance values were greater than .02 , indicating no issues with collinearity (Menard, 1995; Myers, 1990).

\section{Structural Equation Modeling}

SEM was then conducted to determine if the model was a good fit for the data and whether the model demonstrated invariance for parents of children with and without ASD. The total sample size of 254 was acceptable. As previously detailed, a minimum sample size of 230 was required to detect a moderate effect and achieve a power of .95 . However, splitting the sample into parents of children with and without ASD resulted in sample sizes that were sub-optimal (Brown, 2006). Communication skills, aggressive behaviour, perceived 
limit setting ability, social support, and depression were used as marker indicators and therefore their unstandardised factor loadings were set at 1.00 (Brown, 2006).

The indicators were normally distributed. There were no issues with kurtosis, except for economic support. According to Kim's (2013) criterion, skewness values were only problematic for depression, anxiety, social interactions, conduct problems and aggressive behaviour (all of which were positively skewed). This was expected, due to the sample comprising parents of children with and without ASD. The parents of children without ASD are a normative sample and therefore had lower mean scores (closer to the normal range on all variables), resulting in a positive skew. Previous research has shown that the DASS and the SCQ demonstrate positive skew when tested in normative samples (Henry \& Crawford, 2005; Mulligan et al., 2009). The large sample and the use of ML estimation method means that the analysis is somewhat robust to violations of normality (Chou \& Bentler, 1995). Chou, Bentler, \& Satorra, (1991) found that ML was robust against skew when there were no issues with kurtosis (as was the case for all skewed variables in this analysis). Thus, transformations were not conducted on these variables.

The model was first tested in parents of children with ASD to determine whether Model A would be validated in a new sample. The goodness of fit values for the model were $\chi^{2}(38, N=138)=53.24, p=.0514, C F I=.968, T L I=.954$, RMSEA $=.054,90 \% C I[.000$, $.086], S R M R=.069$. The $\chi^{2}$ value was non-significant, indicating good fit. According to the cut-off values outlined earlier, all fit indices indicated that Model A was a good fit for the observed data, with CFI and TLI values above .95, RMSEA below .06, and SRMR below .08 .

Unstandardised factor loadings can be interpreted as the unit increase in that variable that occurs when there is a 1-unit increase in the latent factor (Brown, 2006). Completely standardised factor loadings can be interpreted as the standard score increase in that variable 
that occurs when there is a 1-unit standard score increase in the latent factor (Brown, 2006). Completely standardised loadings can also be interpreted as the correlation between the indicator and the factor (Brown, 2006). As variables are often measured on different scales, completely standardised estimates can be easier to interpret (Ullman, 2006). Furthermore, the use of standardised estimates allows for the comparison of the magnitude of factor loadings and regression coefficients (Weston \& Gore, 2006). Completely standardised factor loadings/coefficients are therefore reported.

In the ASD sample, all completely standardised factor loadings (STDYX) were significant $(p<.05)$, meaning that all indicators loaded significantly onto their latent factor. All factor loadings were also above .3, indicating salience (Brown, 2006). The factor loading for social interactions was above 1.00, indicating a Heywood case, however, this was likely due to the small sample size (Brown, 2006). Factor loadings are presented in Table 6. 
Table 6

STDYX Factor Loadings for Model A, in Parents of Children with ASD

\begin{tabular}{llcc}
\hline Factor & Indicator & Loading & $S E$ \\
\hline Child Social and & & & \\
Interpersonal Deficits & & $.521^{* *}$ & .115 \\
& Communication Skills & $1.025^{* *}$ & .192 \\
& Social Interactions & & \\
Externalising Behaviour & & $.887^{* *}$ & .090 \\
& Aggressive Behaviour & $.693^{* *}$ & .085
\end{tabular}

Maladaptive Parental

Cognitions

$\begin{array}{lll}\text { Perceived Limit Setting Ability } & .509 * * & .082 \\ \text { Parental Locus of Control } & .831^{* *} & .086\end{array}$

Socio-Economic Support

$\begin{array}{lll}\text { Social Support } & .858^{* *} & .079 \\ \text { Economic Support } & .586^{* *} & .081\end{array}$

Parental Distress

$\begin{array}{lll}\text { Depression } & .798^{* *} & .040 \\ \text { Anxiety } & .801 * * & .037 \\ \text { Stress } & .912 * * & .029\end{array}$

Note. $S E=$ Standard Error.

$* *=p<.001$. 
All regression pathways in the model were significant $(p<.05)$, with the exception of externalised behaviour on child social and interpersonal deficits $(p=.056)$. Parental distress was negatively predicted by socio-economic support, with lower socio-economic support predicting increased parental distress, and positively predicted by maladaptive parental cognitions, with higher levels of maladaptive parental cognitions (more external LOC and lower limit setting ability) predicting increased parental distress. Socio-economic support was negatively predicted by child social and interpersonal deficits, with increased deficits predicting decreased support. Maladaptive parental cognitions were negatively predicted by socio-economic support, with lower socio-economic support predicting increased maladaptive parental cognitions, and positively predicted by externalised behaviour, with increased externalised behaviour predicting increased maladaptive parental cognitions. Externalised behaviour was positively predicted by child social and interpersonal deficits, with increased deficits associated with increased externalised behaviour. These pathways were all as expected based on the literature. Regression coefficients are presented in Table 7. 
Table 7

STDYX Regression Coefficients for Model A, in Parents of Children with ASD

\begin{tabular}{lll}
\hline Factor & $B$ & $S E$
\end{tabular}

Parental Distress ON

$\begin{array}{lll}\text { Socio-Economic Support } & -.474^{* *} & .120 \\ \text { Maladaptive Parental } & .232^{*} & .117 \\ \text { Cognitions } & & \end{array}$

Socio-Economic

Support ON

Child Social and Interpersonal $\quad-.343^{*} \quad .119$

Deficits

Maladaptive Parental

Cognitions ON

$\begin{array}{lll}\text { Socio-Economic Support } & -.446^{* *} & .110 \\ \text { Externalised Behaviour } & .579^{* *} & .123\end{array}$

Externalised

Behaviour ON

Child Social and Interpersonal .199 .104

Deficits

Note. $B=$ Beta, completely standardised regression coefficient; $S E=$ Standard Error $*=p<.05 . * *=p<.001$.

The Heywood case and non-significant regression pathway between externalised behaviour and child social and interpersonal deficits was likely a result of the small sample size. When conducting SEM it is preferable to have a high ratio of number of observations to 
number of estimated parameters (N:q ratio; Jackson, 2003). Blunch (2013) and Kline (2005) recommend sample sizes of 10-20 per free parameter, or at least 200-300 observations for complex models. The current sample of 138 was likely to have been too small and therefore lacked power for the complexity of the model. Small sample sizes can cause problems with the calculation of Standard Error (SE), specifically resulting in large values (Brown, 2006). SE estimates the amount of sampling error, and therefore larger SE's indicate that the model has more error and is less stable (Brown, 2006). The significance of a coefficient is determined by calculating a $\mathrm{z}$ value, which is the coefficient divided by its SE. Large SE's therefore reduce the likelihood of a coefficient being significant. This is likely why the regression coefficient for externalised behaviour on child social and interpersonal deficits was non-significant. As the fit indices were acceptable, it suggests that the model is still valid and has clinical utility, supporting the finding by Falk et al. (2014).

The model was then tested in parents of children without ASD; however, the model was unable to converge. This was likely due to the small sample size, meaning that there were not enough observations for the number of estimates required for the model. Nonconvergence (improper solution) is more likely to happen when sample sizes are small, and models are complex (Brown, 2006; Jackson, 2003). Invariance testing could therefore not be conducted.

The model was then tested in the entire sample to determine whether it was a good fit when both parental groups were included. The goodness of fit values for the model were $\chi^{2}$ $(38, N=252)=73.56, p=.0005, C F I=.969, T L I=.955, R M S E A=.061,90 \% C I[.040$, $.082], S R M R=.055$. The $\chi^{2}$ value was significant, indicating poor fit; however, this is likely due to the large sample size (Brown, 2006). All fit indices indicated that Model A was a good fit for the data, with CFI and TLI values above .95, RMSEA at around .06, and SRMR below .08 . 
All completely standardised factor loadings were significant $(p<.05)$, meaning all indicators loaded significantly onto their latent factor. Furthermore, all factor loadings were above .3, indicating salience (Brown, 2006). All regression pathways in the model were significant $(p<.05)$ and were in the same directions as in the ASD sample. Factor loadings and regression coefficients are presented in Table 8 and 9 respectively. 
Table 8

STDYX Factor Loadings for Model A, in Whole Sample

\begin{tabular}{llll}
\hline Factor & Indicator & Loading & $S E$
\end{tabular}

Child Social and

Interpersonal Deficits

$\begin{array}{lll}\text { Communication Skills } & .720^{* *} & .044 \\ \text { Social Interactions } & .949^{* *} & .041\end{array}$

Externalising Behaviour

$\begin{array}{lll}\text { Aggressive Behaviour } & .790 * * & .040 \\ \text { Conduct Problems } & .824 * * & .039\end{array}$

Maladaptive Parental

Cognitions

$\begin{array}{lll}\text { Perceived Limit Setting Ability } & .759 * * & .039 \\ \text { Parental Locus of Control } & .829 * * & .036\end{array}$

Socio-Economic Support

Social Support

$.840 * * \quad .058$

Economic Support

$.593 * *$

.059

Parental Distress

Depression

$.784 * * \quad .030$

Anxiety

$.839 * * \quad .025$

Stress

$.900 * *$

Note. $S E=$ Standard Error.

$* *=p<.001$. 
Table 9

STDYX Regression Coefficients for Model A, in Whole Sample

\begin{tabular}{lll}
\hline Factor & $B$ & $S E$
\end{tabular}

Parental Distress ON

$\begin{array}{lll}\text { Socio-Economic Support } & -.544 * * & .099 \\ \text { Maladaptive Parental } & .211^{*} & .096 \\ \text { Cognitions } & & \end{array}$

Socio-Economic

Support ON

Child Social and Interpersonal $\quad-.632^{* *} \quad .069$

Deficits

Maladaptive Parental

Cognitions ON

$\begin{array}{lll}\text { Socio-Economic Support } & -.389 * * & .079 \\ \text { Externalised Behaviour } & .649 * * & .067\end{array}$

Externalised

Behaviour ON

Child Social and Interpersonal $\quad .452 * * \quad .067$

Deficits

Note. $B=$ Beta, completely standardised regression coefficient; $S E=$ Standard Error.

$*=p<.05 . * *=p<.001$. 


\section{Discussion}

The prediction of parental distress is extremely complex, with multiple factors likely to contribute (Falk, 2012). Model A, developed by Falk et al. (2014) highlights four factors in the prediction of distress in the parents of children with ASD: child social and interpersonal deficits, externalised behaviour, maladaptive parental cognitions, and socio-economic support.

The first hypothesis, that Model A would be validated in a new sample, was supported. The model was tested in parents of children with ASD and all fit indices were of an acceptable level, indicating good fit. Furthermore, all factor loadings and regression coefficients were significant, with the exception of the regression coefficient for externalised behaviour on child social and interpersonal deficits. There was also a Heywood case, as the completely standardised factor loading for social interactions was greater than 1 . However, as outlined earlier, both of these issues are likely due to the small sample size. These results indicate that maladaptive parental cognitions and socio-economic support mediate the relationship between child social and interpersonal deficits and externalised behaviour with parental distress. This finding is consistent with Falk et al. (2014). However, is inconsistent with previous researchers who have found a direct relationship between ASD severity and externalised behaviour with parental distress (Davis \& Carter, 2008; McStay et al., 2013).

The second hypothesis, that the model would not demonstrate invariance, was not supported. Due to model non-convergence (likely due to the small sample size) invariance testing could not be conducted. Instead, the model was tested in the entire sample to determine whether it was a good fit when both parental groups were included in the analysis. The results were inconsistent with the second hypothesis, as the model was a good fit for the whole sample, as all fit indices were of an acceptable level. Furthermore, all factor loadings and regression coefficients were significant. This finding provides preliminary evidence that 
Model A has universality, meaning that it may be effective at predicting parental distress across parental groups. It is therefore argued that distress in the parents of children with ASD is not predicted by unique factors, but instead by the same factors that predict parental distress in general. Any difference in distress between parental groups is therefore due to differences in the magnitude of scores on these factors. This was supported by the current findings, as parents of children with and without ASD were found to significantly differ on every indicator, with parents of children with ASD having significantly higher levels of child social and interpersonal deficits, externalised behaviour, and maladaptive parental cognitions, and significantly lower levels of socio-economic support, compared to parents of children without ASD.

Thus there are two main findings from the current study. Firstly, the model was replicated in a new sample, demonstrating its ability to effectively predict distress in the parents of children with ASD. This finding provides further evidence that parent-centric factors (socio-economic support and maladaptive cognitions) are the most important predictors of distress in this parental group. Interventions that aim to reduce parental distress should therefore target these factors. Furthermore, these factors are easier to target in parental interventions, compared to child-centric factors (social and interpersonal deficits and externalised behaviour). It is argued that the high prevalence of distress in parents of children with ASD warrants the consideration of parent-focused interventions in the treatment of ASD in general. This contrasts strongly with current treatment approaches, which focus almost exclusively on the child (Gavita, et al., 2011; Keen et al., 2010).

Secondly, this study provides preliminary evidence that Model A may effectively predict parental distress in general, rather than specifically in relation to ASD. This suggests that Model A could be used to develop interventions that effectively prevent/treat parental distress in not only parents of children with ASD, but also parents of children with Down 
syndrome, mental retardation, ADHD, or normative populations. However, further research would be required to determine whether Model A can predict distress in these groups, as the current study only examined parents of children with and without ASD. Future research should also conduct invariance testing in parents of children with and without ASD.

\section{Current ASD Treatments}

As mentioned earlier, behavioural interventions are the dominant treatment approach for ASD (Ospina et al., 2008). This has resulted in increased parental involvement, as parents are often trained in how to implement behavioural interventions at home (Harris, 1984). Parental involvement requires some form of parent training/intervention in order to educate parents on how to implement interventions effectively. Parental interventions can help ensure the child's home environment enhances their progress, however, also provide a unique opportunity to address the parental experience, including the prevention/treatment of distress (Gavita \& Joyce, 2008; Keen et al., 2010).

Many parents of children with ASD are primarily concerned with their child's functioning (Gavita et al., 2011). However, parents should also be aware of the influence that their mental health can have on their ability to effectively implement interventions (Gavita et al., 2011). As mentioned earlier, increased parental distress has been shown to result in decreased child progress, and increased externalised behaviour (Lecavalier et al., 2006; Osborne et al., 2008). It is therefore recommended that parental distress be assessed at the beginning of ASD treatment, in order for therapists/clinicians to identify/refer parents with high distress in order to improve both parent and child outcomes (Osborne et al., 2008). Furthermore, it is recommended that ASD interventions take a more holistic approach, and address parental distress by including parent-focused elements alongside the management of child-focused elements. 


\section{Cognitive Behavioural Therapy}

Cognitive Behavioural Therapy (CBT) refers to a range of treatment techniques that are based on the idea that inaccurate beliefs, maladaptive thoughts, and unhelpful behaviours precipitate and maintain mental disorders (Driessen \& Hollon, 2010; Hollon et al., 2002). The aim of CBT is to teach the client techniques they can use to manage their distress (Beck, 2011).

CBT is the most empirically supported treatment available, with research demonstrating its efficacy in the treatment of both mood and anxiety disorders, symptoms of which have been found to be elevated in the parents of children with ASD (Driessen \& Hollon, 2010; Hoffman \& Smits, 2008). Furthermore, there is evidence that CBT reduces symptoms and relapse risk in the long-term, even once treatment has ended (Cuijpers et al., 2012; Driessen \& Hollon, 2010). CBT can also prevent the onset of mood and anxiety disorders and symptoms in individuals who are considered at risk (Clark et al., 2001; Hollon et al., 2002). CBT techniques could therefore be used to not only treat parents experiencing clinically significant levels of distress, but also mitigate subclinical distress.

\section{Addressing socio-economic support using CBT.}

Social support is considered an important moderator in both mood and anxiety disorders, with lower levels increasing risk of these disorders (Dour et al., 2014). However, the current findings suggest that social support is also a mediating variable, meaning that increasing socio-economic support may result in reduced distress.

Socio-economic support could be improved by increasing the number and quality of support services available for parents of children with ASD (Dour et al., 2014; Ekas et al., 2010). This could be the first step in helping prevent parental distress, as increased received support is likely to result in increased perceived support, which is associated with decreased distress (Martin, Reece, Lauder \& McClelland, 2011). Furthermore, increased availability of 
support services could ensure that parents access services early, potentially preventing distress. However, cognitive models argue that perceived support is not purely a consequent of the objective amount of support received, with cognitive factors also playing a role (Brand, Lakey \& Berman, 1995). Consistent with this, Martin et al. (2011) found only a moderate correlation between received and perceived support, suggesting that other factors contribute to perceived support. It is therefore argued that perceived support could be increased through a combination of providing increased support services, as well as through CBT-based techniques (Brand et al., 1995). Furthermore, CBT-based techniques could be used to teach parents how to develop support networks and engage more effectively with support (Hogan, Linden \& Najarian, 2002; Martin et al., 2011).

There is limited research examining the efficacy of CBT-based interventions to increase perceived support (Dour et al., 2014), particularly in parents. Martin et al., (2011) examined the effect of a 10-week intervention, compared to a waitlist-control group, on perceived and received social support in 81 individuals from a community sample. The intervention was based on CBT techniques, including social skills training, psychoeducation, and identifying and addressing unhelpful cognitions. It was found that the intervention was effective at increasing perceived support, but not received support, from pre-test to post-test. This supports the idea that perceived support can be increased through techniques other than increasing received support. Furthermore, this intervention was effective at reducing depression scores from pre-test to post-test, suggesting that interventions targeting perceived social support may be effective at alleviating depressive symptoms. Dour et al. (2014), Brand et al. (1995) and Maria and Filimon (2010) have also found that CBT-based interventions are effective at increasing perceived social support, and potentially reducing depression and anxiety symptoms. 
There is a lack of research examining the effect of interventions to target economic support, potentially because accessing additional economic support is often unfeasible, and therefore not a focus for research. However, based on the above research, it is argued that CBT-based interventions could be used to increase perceived socio-economic support and subsequently reduce distress in the parents of children with ASD.

\section{Addressing maladaptive parental cognitions using CBT.}

The importance of parental cognitions in predicting parental distress is hardly surprising when the role of maladaptive cognitions in the onset and maintenance of mood and anxiety disorders is considered (Driessen \& Hollon, 2010). Furthermore, there is increasing support for the use of cognitive techniques in parent training and interventions (Gavita \& Joyce, 2008; Gavita et al., 2011).

A key aspect of CBT is teaching the client to identify, evaluate, and respond to their maladaptive thoughts and beliefs (Beck, 2011). CBT-based techniques could therefore be used to address maladaptive parental cognitions in parents of children with ASD.

There is limited research examining the effectiveness of CBT-based interventions to reduce distress in the parents of children with ASD. Tonge et al. (2006) compared a CBTbased parent education and behaviour-management intervention and a parent education and counselling intervention on mental health in parents of children with ASD. It was found that both interventions were effective at improving parental anxiety and depression from baseline to 6-month follow up. However, the CBT-based intervention alleviated a greater percentage of anxiety symptoms, suggesting that parent-focused interventions effectively reduce distress in the parents of children with ASD, but CBT-based interventions may be particularly effective.

Furthermore, Gavita and Joyce (2008) found that parental interventions containing cognitive elements were more effective at reducing parental distress and child externalised 
behaviour compared to non-cognitive interventions in a sample of parents of children with externalised behaviour. Parents who participated in cognitive interventions also reported greater satisfaction with the intervention and demonstrated greater parenting skill post intervention, compared to parents who participated in non-cognitive interventions (Gavita \& Joyce, 2008).

Similar results have been found in parents of children with intellectual and developmental disabilities (Hastings \& Beck, 2004; Singer, Ethridge, \& Aldana, 2007). Hastings and Beck (2004) conducted a review of 6 studies and found that CBT-based interventions for parents of children with an intellectual disability were effective at reducing parental distress and were more effective in reducing parental distress than child-focused interventions, such as ABA or alternative parent-focused interventions, such as support groups.

Singer et al. (2007) conducted a meta-analysis of 17 studies examining the effectiveness of parent-focused interventions to reduce distress in parents of children with a developmental disability. CBT-based interventions were found to be effective at reducing parental distress. However, interventions that combined CBT and parent training aspects had greater effect sizes, suggesting that a holistic treatment approach comprising both parent and child aspects could be most effective at reducing distress.

None of the studies within these articles examined the effect of parent-focused CBT interventions on child outcomes. However, Singer et al. (2007) and Hastings and Beck (2004) both argue that CBT-based interventions targeting parental distress are also likely to result in improved child outcomes, potentially via improved parenting techniques.

\section{Limitations}

The current study was a correlational design, therefore the results are not conclusive evidence of the relationship between maladaptive parental cognitions and socio-economic 
support with parental distress. Future research could examine this relationship in a longitudinal design to provide increased support for the efficacy of Model A to predict distress in the parents of children with ASD.

Secondly, there are potential sampling issues in the current study. Participants were primarily recruited through ASD support groups and organisations. Parents who are connected to a support group or organisation may systematically differ from parents who are not (Weiss, Tint, Paquette-Smith \& Lunsky, 2015). For example, parents in this study may have increased levels of support, be coping better, and have less distress. Furthermore, there may be differences in the severity of their child's ASD, with parents seeking support potentially having children with more severe ASD.

An additional sampling issue is that the majority of parents in the current study (66\%) were primary carers for their child. Therefore, these results are not representative of parents who take on a smaller caring role. It is possible that distress in parents who are not primary carers is predicted by alternative or additional factors (Falk, 2012). Further research in this area is required.

Thirdly, the current study relied on parental report for ASD diagnosis, rather than a formal measure. Furthermore, the current study used self-report measures of child social and interpersonal deficits and externalised behaviour. These were the best options available, as the nature of online surveys makes it difficult to accurately assess ASD diagnosis or child behaviour. However, self-reports may be inaccurate due to parental beliefs about their child, or the parents' mental state, among other factors (Eaves et al., 2006). Future research could examine parental dyads and compare parental reports, or use more objective measures of child diagnosis and behaviour.

Fourthly, the current study had a small sample size when the sample was split into parents of children with and without ASD. Ideally for SEM to be conducted sample sizes of 
10-20 participants per freely estimated parameter or around 200-300 participants are required (Blunch, 2013; Kline, 2005). Therefore, the sample sizes of 138 for the ASD sample, and 114 for the non-ASD sample were smaller than optimal. However, as the model fit indices were of an acceptable level in the ASD and whole sample, it is concluded that the model is still a good fit and has clinical utility.

A further limitation is that the current study did not examine all possible predictors of distress, instead only those within the model were examined. These variables were selected because of the findings by Falk et al. (2014). Furthermore, this was done to limit the length of the survey in order to increase responses. However, it is possible that there are other variables that contribute to parental distress, such as quality of life, coping strategies, parent-child interactions, caregiver burden, or cognitions unrelated to parenting such as general LOC (Beurkens, Hobson \& Hobson, 2013; Cooley, Veldorale-Griffin, Petren, \& Mullis, 2014; Falk, 2012; Weiss et al., 2015). Future research could examine the effectiveness of additional factors to predict parental distress.

Another limitation is the use of economic support and aggressive behaviour measures that have not been psychometrically validated. However, these measures were selected as there is a lack of short, online, psychometrically validated scales that assess economic support and child aggressive behaviour. The length of the questionnaire was an important consideration, therefore short measures were selected in order to reduce fatigue and facilitate completion. Furthermore, these scales have been used previously by Falk et al. (2014), and the economic support measure was found to have acceptable internal consistency in both the current study and Falk et al. (2014).

A final limitation is the small number of fathers in the current study $(\mathrm{N}=38,11 \%)$. This meant that invariance testing on parent sex could not be conducted. However, Falk et al. (2014) found that Model A was a good fit for both mothers and fathers of children with ASD. 
Furthermore, the unequal sample sizes in the current study may reflect the real world distribution of primary carers, with research finding that up to $90 \%$ of reported primary carers are female (Beurkens et al., 2013). However, this may not be an accurate reflection of the sex distribution, as female primary carers may be more likely to engage in research than male primary carers (Davis \& Carter, 2008). Future research should aim to conduct invariance testing for mothers and fathers of children with ASD in order to provide additional support for Falk et al.'s (2014) finding.

\section{Future Research}

As mentioned previously, future research could conduct invariance testing of Model A in parents of children with and without ASD and mothers and fathers, as well as further examination of non-primary carers. Furthermore, research could also examine parental dyads to determine whether Model A predicts distress in both parents of the same child(ren), as previous research has not addressed this.

Future research could also map existing interventions onto Model A, to determine whether these interventions are effectively targeting the factors predictive of parental distress. Most ASD interventions target child-centric factors, and parental involvement tends to focus on ASD psychoeducation, or the implementation of child-focused behavioural interventions (Gavita et al., 2011; Keen et al., 2010). It is therefore expected that current interventions will not map well onto Model A.

Future research could also use Model A to develop a new parental intervention, or alter an existing parent or child intervention, in order to prevent/treat parental distress. This intervention should target parent-centric variables such as maladaptive parental cognitions and socio-economic support, and as mentioned earlier, a CBT-based intervention could be particularly effective. If existing interventions are modified, addressing maladaptive cognitions should not be an add-on at the end of the intervention, but should be addressed 
early and considered throughout (Gavita et al., 2011). Any interventions that aim to identify and modify maladaptive parental cognitions should be specific and focus on cognitions related to parenting (Gavita et al., 2011). This will help parents effectively apply the strategies in the real world, increasing the chance of long-term success (Gavita et al., 2011).

\section{Conclusion}

The current study demonstrated that parents of children with ASD have significantly higher levels of distress compared to parents of children without ASD. As previous research has found that parental distress can negatively impact upon both parent and child functioning, it is argued that the prevention and treatment of parental distress should be considered a primary concern when treating children with ASD.

This study provides further empirical validation for Model A to predict distress in the parents of children with ASD, and supports the finding by Falk et al. (2014) that the relationship between child social and interpersonal deficits and externalised behaviour with parental distress is mediated by socio-economic support and maladaptive parental cognitions. Based on this finding, it is recommended that ASD interventions consider a more holistic approach by including techniques to address maladaptive parental cognitions, and socioeconomic support alongside the management of child-focused aspects. Furthermore, it is suggested that CBT-based interventions could be particularly effective at reducing maladaptive parental cognitions and increasing socio-economic support, which could subsequently reduce parental distress.

The finding that socio-economic support and maladaptive parental cognitions play a major role in predicting distress in the parents of children with ASD is substantial. This finding suggests that while child-centric variables are important, they are not the key predictors and therefore, should not be the key focus of parental interventions. Interventions that purely focus on the child are not only likely to be ineffective at reducing parental 
distress, but may also produce sub-optimal child outcomes. In conclusion, while the child with ASD is undeniably important, the focus when providing support services to parents of children with ASD should not be only on the child, but on the parent/s as well. 


\section{References}

Altiere, M. J. (2006). Family functioning and coping behaviors in parents of children with Autism (Unpubished master's thesis). Eastern Michigan University, Michigan.

Altiere, M. J. \& Von Kluge, S. (2009). Searching for acceptance: Challenges encountered while raising a child with Autism. Journal of Intellectual \& Developmental Disability, 34, 142-152. doi:10.1080/13668250902845202.

American Psychiatric Association. (2013). Diagnostic and Statistical Manual of Mental Disorders. $5^{\text {th }}$ edition. Arlington, VA: American Psychiatric Association.

Antony, M. M., Bieling, P. J., Cox, B, J., Enns, M. W. \& Swinsom, R. P. (1998). Psychometric properties of the 42-item and 21-item versions of the depression anxiety stress scales in clinical groups and a community sample. Psychological Assessment 10, 176-181. doi: 10.1037/1040-3590.10.2.176.

Australian Bureau of Statistics (2007). Australian National Survey on Mental Health and Wellbeing: Summary of results. Retrieved May $25^{\text {th }} 2017$ from $<$ http://www.ausstats.abs.gov.au/Ausstats/subscriber.nsf/0/6AE6DA447F985FC2CA2 574EA00122BD6/\$File/43260_2007.pdf >.

Australian Bureau of Statistics (2012). Autism in Australia: Prevalence of Autism. Retrieved March $17^{\text {th }} 2017$ from <http://www.abs.gov.au/ausstats/abs@.nsf/Latestproducts/4428.0Main\%20Features32 012 opendocument $\&$ tabname $=$ Summary $\&$ prodno $=4428.0 \&$ issue $=2012 \&$ num $=\&$ view $=>$.

Bebko, J. M., Konstantareas, M. M. \& Springer, J. (1987). Parent and professional evaluations of family stress associated with characteristics of Autism. Journal of Autism and Developmental Disorders, 17, 565-576. doi:10.1007/BF01486971. 
Beck, J. S. (2011). Cognitive Behavioural Therapy: Basics and Beyond. $2^{\text {nd }}$ ed. Guilford Press: New York.

Bentler, P. M. (1990). Comparative fit indexes in structural models. Psychological Bulletin, 107, 238-246. doi:10.1037/0033-2909.107.2.238.

Beurkens, N. M., Hobson, J. A. \& Hobson, R. P. (2013). Autism severity and qualities of parent-child relations. Journal of Autism and Developmental Disorders, 43, 168-178. doi:10.1007/s10803-012-1562-4.

Bishop, S. J. (2007). Neurocognitive mechanisms of anxiety: An integrative account. Trend in Cognitive Sciences, 11, 307-316. doi:10.1016/j.tics.2007.05.008.

Bitsika, V. \& Sharpley, C. F. (2004). Stress, anxiety and depression among parents of children with Autism Spectrum Disorder. Australian Journal of Guidance \& Counselling, 14, 151-161. doi:10.2147/NDT.S107103.

Bland, J. M. \& Altman, D. G. (1997). Statistics notes: Cronbach's alpha. British Medical Journal, 314, 572. doi:10.1136/bjm.314.7080.572.

Blunch, N. L. (2013). Introduction to structural equation modelling using IBM SPSS statistics and AMOS. Sage Publications: London.

Brand, E. F., Lakey, B. \& Berman, S. (1995). A Preventive, psychoeducational approach to increase perceived social support. American Journal of Community Psychology, 23, 117-135. doi:10.1007/BF02506925.

Bromley, J., Hare, D. J., Davison, K. \& Emerson, E. (2004). Mothers supporting children with Autistic Spectrum Disorders: Social support, mental health status and satisfaction with services. Autism, 8, 409-423. doi:10.1177/1362361304047224.

Brown, T. A. (2006). Confirmatory Factor Analysis For Applied Research. Guilford Press: New York 
Campis, L. K., Lyman, R. D., \& Prentice-Dunn, S. (1986). The parental locus of control scale: Development and validation. Journal of Clinical Child Psychology, 15, 260267. doi:10.1207/s15374424jccp1503_10.

Chou, C. P. \& Bentler, P. M. (1995). Estimates and Tests in Structural Equation Modelling. In R. H. Hoyle (Ed.), Structural Equation Modelling: Concepts, issues, and applications (pp. 37-55). Thousand oaks, CA: Sage.

Chou, C. P., Bentler, P. M. \& Satorra, A. (1991). Scaled test statistics and robust standard errors for non-normal data in covariance structure analysis: A Monte Carlo study. British Journal of Mathematical and Statistical Psychology, 44, 347-357. doi:10.1111/j.2044-8317.1991.tb00966.x.

Clarke, G. N., Hornbrrok, M., Lynch, F., Polen, M., Gale, J., Beardslee, W., ... Seeley, J. (2001). A randomized trial of a group cognitive intervention for preventing depression in adolescent offspring of depressed parents. Archives of General Psychiatry, 58, 1127-1134. doi:10.1001/archpsyc.58.12.1127.

Cobb, S. (1976). Social support as a moderator of life stress. Psychosomatic Medicine, 38, 300- 314. doi:10.1097/00006842-197609000-00003.

Cohen, S., Kessler, R. C. \& Gordon, U. L. (1995). Strategies for measuring stress in studies of psychiatric and physical disorder. In: Cohen, S., Kessler, R. C., \& Gordon, U. L. eds. Measuring Stress: A Guide for Health and Social Scientists. New York, NY: Oxford University Press: 3-26.

Coleman, P. K. \& Karraker, K. H. (1997). Self-efficacy and parenting quality: Findings and future applications. Developmental Review, 18, 47-85. doi:10.1006/drev.1997.0448.

Cooley, M. E., Veldorale-Griffin, A., Petren, R. E. \& Mullis, A. K. (2014). Parent-child interaction therapy: A meta-analysis of child behavior outcomes and parent stress. Journal of Family Social Work, 17, 191-208. doi:10.1080/10522158.2014.8886. 
Cuijpers, P., Van Straten, A., Driessen, E., Van Oppen, P., Bockting, C. L. H. Andersson, G. (2012). Depression and dysthymic disorders. In: Hersen, M.;Sturmey, P. (eds). Handbook of Evidence-Based Practice in Clinical Psychology. Vol II. Adult disorders. Wiley, USA: (in press)

Davis, N. O. \& Carter, A. S. (2008). Parenting stress in mothers and fathers of toddlers with Autism Spectrum Disorders: Associations with child characteristics. Journal of Autism and Developmental Disorders, 38, 1278-1291. doi:10.1007/s10803-007-0512-z.

Donenberg, G. \& Baker, B. L. (1993). The impact of young children with externalizing behaviors on their families. Journal of Abnormal Child Psychology, 21, 179-198. doi:10.1007/BF00911315.

Dour, H. J., Wiley, J. F., Rpy-Byrne, P., Stein, M. B., Sullivan, G., Sherbourne, C. D., ... Craske, M. G. (2014). Perceived social support mediates anxiety and depressive symptom changes following primary care intervention. Depression and Anxiety, 31, 436-442. doi:10.1002/da.22216.

Downey, R. G. \& King, C. V. (1998). Missing data in likert ratings: A comparison of replacement methods. Journal of General Psychology, 125, 175-191. doi:10.1080/00221309809595542.

Driessen, E. \& Hollon, S, D. (2010). Cognitive behavioural therapy for mood disorders: Efficacy, moderators and mediators. Psychiatric Clinics of North America, 33, 537555. doi:10.1016/j.psc.2010.04.005.

Eaves, L. C., Wingert, H. D., Ho, H. H. \& Mickelson, E. C. R. (2006). Screening for Autism Spectrum Disorders with the social communication questionnaire. Developmental and behavioural pediatrics, 27, 95-103. doi:10.1097/00004703-200604002-00007.

Ekas, N. V., Lickenbrock, D. M., \& Whitman, T. L. (2010). Optimism, social support, and 
well-being in mothers of children with Autism Spectrum Disorder. Journal of Autism and Developmental Disorders, 40, 1274-1284.

doi:10.1007/s10803-010-0986-y.

Falk, N. (2012). The factors predicting stress, anxiety and depression in the parents of children with autism (Unpublished doctoral dissertation). University of Tasmania, Hobart.

Falk, N. H., Norris, K. \& Quinn, M. G. (2014). The factors predicting stress, anxiety and depression in the parents of children with Autism. Journal of Autism and Developmental Disorders, 44, 3185-3203. doi:10.1007/s10803-014-2189-4.

Forand, N. R. \& DeRubeis, R. J. (2014). Extreme response style and symptom return after depression treatment: The role of positive extreme responding. Journal of Consulting and Clinical Psychology, 82, 500-509. doi:10.1037/a0035755.

Fong, P. L. (1991). Cognitive appraisals in high- and low-stress mothers of adolescents with Autism. Journal of Consulting and Clinical Psychology, 59 (3), 471-474. $<$ http://www.apa.org/pubs/journals/ccp/>.

Gavita, O. A. \& Joyce, M. R. (2008). A review of the effectiveness of group cognitively enhanced behavioural based parent programs designed for reducing disruptive behaviour in children. Journal of Cognitive and Behavioral Psychotherapies. 8 (2), 185-199. <http://jcb-psychotherapies.com/>.

Gavita, O. A., Joyce, M. R. \& David, D. (2011). Cognitive behavioral parent programs for the treatment of child disruptive behavior. Journal of Cognitive Psychotherapy: An International Quarterly, 25, 240-256. doi:10.1891/0889-8391.25.4.240.

Gerard, A. B. (1994). Parent-child relationship inventory (PCRI) manual. Los Angeles, CA: Western Psychological Services. 
Goodman, R. (1997). The strengths and difficulties questionnaire: A research note. Journal of Child Psychology and Psychiatry, 38, 581-586. doi:10.1111/j.1469-7610.1997.tb01545.x.

Goodman, R. (2001). Psychometric properties of the strengths and difficulties questionnaire. Journal of the American Academy of Child and Adolescent Psychiatry, 40, 13371345. doi:10.1097/00004583-200111000-00015.

Gray, D. E. (2002). 'Everybody just freezes. Everybody is just embarrassed’: Felt and enacted stigma among parents of children with high functioning Autism. Sociology of Health and Illness, 24, 734-749. doi:10.1111/1467-9566.00316.

Hagekull, B., Bohlin, G. \& Hammarberg, A. (2001). The role of parental perceived control in child development: A longitudinal study. International Journal of Behavioral Development, 25, 429-437. doi:10.1080/01650250042000438.

Happé, F., Ronald, A. \& Plomin, R. (2006). Time to give up on a single explanation for Autism. Nature Neuroscience, 9, 1218-1220. doi:10.1038/nn1770.

Happé, F. \& Ronald, A. (2008). The 'fractionable Autism triad': a review of evidence from behavioural, genetic, cognitive and neural research. Neuropsychology Review, 18, 287- 304. doi:10.1007/s11065-008-9076-8.

Harris, S. L. (1984). The family and the Autistic child: A behavioral perspective. Family Relations, 33, 127-134. doi:10.2307/584597.

Hassal, R., Rose, J. \& McDonald, J. (2005). Parenting stress in mothers of children with an intellectual disability: The effects of parental cognitions in relation to child characteristics and family support. Journal of Intellectual Disability Research, 49, 405-418. doi:10.1111/j.1365-2788.2005.00673.x. 
Hastings, R. P. \& Beck, A. (2004). Practitioner review: Stress intervention for parents of children with intellectual disabilities. Journal of Child Psychology and Psychiatry 45, 1338-1349. doi: 10.1111/j.1469-7610.2004.00357.x.

Hastings, R. P. \& Brown, T. (2002). Behaviour problems of children with Autism, parental self-efficacy, and mental health. American Journal on Mental Retardation, 107, 222232. doi:10.1352/0895-8017(2002)107<0222:BPOCWA>2.0.CO;2.

Hastings, R. P. \& Johnson, E. (2001). Stress in UK families conducting intensive home-based behavioral intervention for their young child with Autism. Journal of Autism and Developmental Disorders, 31, 327-336. doi:10.1023/A:1010799320795.

Hazel, N. A., Oppenheimer, C. W., Technow, J. R., Young, J. F. \& Hankin, B. L. (2014). Parent relationship quality buffers against the effect of peer stressors on depressive symptoms from middle childhood to adolescence. Developmental Psychology, 50, 2115-2123. doi:10.1037/a0037192.

Henry, J. D. \& Crawford, J. R. (2005). The short-form version of the depression anxiety stress scales (DASS-21): Construct validity and normative data in a large non clinical sample. British Journal of Clinical Psychology, 44, 227-239. doi:10.1348/014466505X29657.

Hoffman, S. G. \& Smits, J. A. J. (2008). Cognitive behavioural therapy for adult anxiety disorders: A meta analysis of randomised placebo-controlled trials. Journal of Clinical Psychiatry, 69, 621-632. doi:10.4088/JCP.v69n0415

Hogan, B. E., Linden, W. \& Najarian, B. (2002). Social support interventions: Do they work? Clinical Psychology Review, 22, 381-440. doi: 1 0.1016/S0272-7358(01)00102-7.

Holden, W. J. \& Gray, D. E. (1992). Psycho-social well-being among the parents of children with Autism. Australian and New Zealand Journal of Developmental Disabilities, 18, 
83-92. doi:10.1080/07263869200034841.

Hollon, S. D., Thase, M. E. \& Markowitz, J. C. (2002). Treatment and prevention of depression. Psychological Science in the Public Interest, 3, 39-77. doi:10.1111/1529-1006.00008.

Hooper, D., Coughlan, J. \& Mullen, M. R. (2008). Structural equation modelling: Guidelines for determining fit. Electronic Journal of Business Research Methods, 6, 53-60. doi:10.0000/PMID35188134.

Hu, L. \& Bentler, P. M. (1999). Cutoff criteria for fit indexes in covariance structure analysis: Conventional criteria versus new alternatives. Structural equation modeling: A multidisciplinary journal, 6, 1-55, doi:10.1080/10705519909540118.

Jackson, D. L (2003). Revisiting sample size and number of parameter estimates: Some support for the n:q hypothesis. Structural Equation Modeling: A Multidisciplinary Journal, 10, 128-141. doi:10.1207/S15328007SEM1001_6.

Kawachi, I. \& Berkman, L. F. (2001). Social ties and mental health. Journal of Urban Health: Bulletin of the New York Academy of Medicine, 78, 458-467. doi:10.1093/jurban/78.3.458.

Keen, D., Couzens, D., Muspratt, S. \& Rodger, S. (2010). The effects of a parent-focused intervention for children with a recent diagnosis of Autism Spectrum Disorder on parenting stress and competence. Research in Autism Spectrum Disorders, 4, 229241. doi:10.1016/j.rasd.2009.09.009.

Kim, H., Y. (2013). Statistical notes for clinical researchers: Assessing normal distribution (2) using skewness and kurtosis. Restorative Dentistry \& Endodontics, 38, 52-54. doi:10.5395/rde.2013.38.1.52.

Kline, R. B. (2005). Principles and Practice of Structural Equation Modeling. $2^{\text {nd }}$ Ed. Guilford Press: New York 
Lecavalier, L. Leone, S. \& Wiltz, J. (2006). The impact of behaviour problems on caregiver stress in young people with Autism Spectrum Disorders. Journal of intellectual Disability Research, 50, 172-183. doi:10.1111/j.1365-2788.2005.00732.x

Lee, G. K., Lopata, C., Volker, M. A., Thomeer, M. L., Nida, R. E., Toomey, J. A., Chow, S. Y. \& Smerbeck, A. M. (2009). Health-related quality of life of parents of children with high-functioning Autism Spectrum Disorders. Focus on Autism and Other Developmental Disabilities, 24, 227-239. doi:10.1177/1088357609347371.

Lovibond, S., \& Lovibond, P. (1995). Manual for the depression anxiety stress scales $\left(2^{\text {nd }}\right.$ ed.). Sydney: Psychology Foundation.

Mackowiak, M. (2000). Aetiology of Autism: Focus on the biological perspective. Early Child Development and Care, 160, 77-84. doi:10.1080/0030443001600107.

Maria, M. \& Filimon, L. (2010). Cognitive restructuring and improvement of symptoms with cognitive-behavioural therapy and pharmacotherapy in patients with depression. Annals of General Psychiatry, 9, S173. doi:10.1186/1744-859X-9-S1-S173.

Martin, P. R., Reece, J., Lauder, S. \& McClelland, A. (2011). A randomised controlled trial of a social support intervention. Applied Psychology: Health and Well-being, 3, 4465. doi:10.1111/j.1758-0854.2010.01044.x

Maughan, D. R., Christiansen, E., Jenson, W. R., Olympia, D. \& Clark, E. (2005). Behavioral parent training as a treatment for externalizing behaviors and disruptive behavior disorders: A meta-analysis. School Psychology Review, 34 (3), 267-286. $<$ http://naspjournals.org/loi/spsr>.

Mazza, G. L., Enders, C. K. \& Ruehlman, L. S. (2015). Addressing item-level missing data: A comparison of proration and full information maximum likelihood estimation. Multivariate Behavioural Research, 50, 504-519. doi:10.1080/00273171.2015.1068157. 
McStay, R., Dissanayake, C., Scheeren, A., Koot, H. M. \& Begeer, S. (2013). Parenting stress and Autism: The role of age, Autism severity, quality of life and problem behaviour of children and adolescents with Autism. Autism, 18, 502-510. doi:10.1177/1362361313485163.

Meirsschaut, M., Roeyers, H. \& Warreyn, P. (2010). Parenting in families with a child with Autism Spectrum Disorder and a typically developing child: Mothers experiences and cognitions. Research in Autism Spectrum Disorders, 4, 661- 669. doi:10.1016/j.rasd.2010.01.002.

Menard, S. (1995). Applied Logistic Regression Analysis. Second Ed. Thousand Oaks, CA: Sage.

Micali, N. Chakrabarti, S., \& Fombonne, E. (2004). The broad Autism phenotype: Findings from an epidemiological survey. Autism, 8, 21-37. doi: 10.1177/1362361304040636.

Mulligan, A., Richardson, T., Anney, R. J. L. \& Gill, M. (2009). The social communication questionnaire in a sample of the general population of school-going children. Irish Journal of Medical Science, 178, 193-199. doi:10.1007/s11845-008-0184-5.

Muthén, L. K., \& Muthén, B. O. (2012). Mplus User's Guide. Seventh Edition. Los Angeles, CA: Muthén \& Muthén.

Myers, R. (1990). Classical and modern regression with applications ( $2^{\text {nd }}$ ed.). Boston, MA: Duxbury.

Myers, S. M. \& Johnson, C. P. (2007). Management of children with Autism Spectrum Disorders. Pediatrics, 120, 1162-1182. doi:10.1542/peds.2007-2362.

Olivier, T. W., Golden, C. J., Acevedo, A., Sterk, V. I., Espinosa, K. M. \& Spengler, K. M. (2013). WAIS-IV index and full scale intelligence quotient score differences between standard and prorated scoring methods. Archives of Assessment Psychology, 3 (1), 57-77. <http://www.assessmentpsychologyboard.org/journal/index.php/AAP>. 
Osborne, L. A., McHugh, L., Saunders, J. \& Reed, P. (2008). Parenting stress reduces the effectiveness of early teaching interventions for Autistic Spectrum Disorders. Journal of Autism and Developmental Disorders, 38, 1092-1103. doi:10.1007/s10803-007-0497-7.

Osborne, L. A. \& Reed, P. (2009). The relationship between parenting stress and behavior problems of children with Autistic Spectrum Disorders. Exceptional Children, 76, 54-73. doi:10.1177/001440290907600103.

Osborne, L. A. \& Reed, P. (2010). Stress and self-perceived parenting behaviors of parents of children with Autistic Spectrum conditions. Research in Autism Spectrum Disorders, 4, 405-414. doi:10.1016/j.rasd.2009.10.011.

Ospina, M. B. Seida, J. K., Clark, B., Karkhaneh, M., Hartling, L., Tjosvold, L., Vandermeer, B. \& Smith, V. (2008). Behavioural and developmental interventions for Autism Spectrum Disorder: A clinical systematic review. PLoS One, 3, e3755. doi:10.1371/journal.pone.0003755.

Pozo, P., Sarria, E. \& Brioso, A. (2011). Psychological adaptation in parents of children with Autism Spectrum Disorders. In M. Mohammadi (Ed.) A Comprehensive Book on Autism Spectrum Disorders (pp 107-130). doi:10.5772/18705.

Reed, P., Howse, J., Ho, B. \& Osborne, L. A. (2016). Relationship between perceived limit setting abilities, Autism Spectrum Disorder severity, behaviour problems and parenting stress in mothers of children with Autism Spectrum Disorder. Autism, 8, 952-959. doi:10.1177/1362361316658775.

Robbins, F, R., Dunlop, G. \& Pleienis, A. J. (1991). Family characteristics, family training, and the progress of young children with Autism. Journal of Early Intervention, 15, 173-184. doi:10.1177/105381519101500206.

Rodrigue, J. R., Morgan, S. B. \& Geffken, G. (1990). Families of Autistic children: 
Psychological functioning of mothers. Journal of Clinical Child Psychology, 19, 371-379. doi:10.1207/s1537442jccp1904_9.

Rotter, J. B. (1966). Generalised expectancies for internal versus external control of reinforcement. Psychological Monographs: General and applied, 80,1-28. doi:10.1037/h0092976.

Rutter, M., Bailey, A., \& Lord, C. (2003). SCQ: Social Communication Questionnaire. Los Angeles, CA:Western Psychological Services.

Seltzer, M. M., Krauss, M. W., Orsmond, G. I. \& Vestal, C. (2001). Families of adolescents and adults with Autism: Uncharted territory. International Review of Research in Mental Retardation, 23, 267-294. doi:10.1016/S0074-7750(00)80014-2.

Schwarzer, R., \& Schulz, U. (2000). Berlin Social Support Scales (BSSS). Retrieved from $<$ www.coping.de $>$.

Singer, G. H. S., Ethridge, B. L. \& Aldana, S. I. (2007). Primary and secondary effects of parenting and stress management interventions for parents of children with developmental disabilities: A meta analysis. Mental Retardation and Developmental Disability Research Reviews, 13, 357-369. doi:10.1002/mrdd.20175.

Tonge, B., Brereton, A., Kiomall, M., MacKinnon, A., King, N. \& Rinehard, N. (2006). Effects on parental mental health of an education and skills training program for parents of young children with Autism: A randomized controlled trial. Journal of the American Academy of Child and Adolescent Psychiatry, 45, 561-569. doi:10.1097/01.chi.0000205701.48324.26.

Tucker, L. R. \& Lewis, C. (1973). A reliability coefficient for maximum likelihood factor analysis. Psychometrika, 38, 1-10. doi:10.1007/BF02291170 
Ullman, J. B. (2006). Structural equation modeling: Reviewing the basics and moving forward. Journal of Personality Assessment, 87, 35-55. doi:10.1207/s15327752jpa8701_03

Umfleet, L. G., Ryan, J. J., Gontkovsky, S. T. \& Morris, J. (2012). Estimating WAIS-IV indexes: Proration versus linear scaling in a clinical sample. Journal of Clinical Psychology, 68 ,390-396. doi:10.1002/jclp.21827.

Van Ginkel, J. R., Sijtsma, K., Van der Ark, A., Vermunt, J. K. (2010). Incidence of missing item scores in personality measurement, and simple item-score imputation. Methodology European Journal of Research Methods for the Behavioral and Social Sciences, 6, 17-30. doi:10.1027/1614-2241/a000003

Weston, R. \& Gore, P. A. (2006). A Brief Guide to Structural Equation Modeling. The Counselling Psychologist, 34, 719-751. doi:10.1177/0011000006286345.

Weiss, M. J., (2002). Hardiness and social support as predictors of stress in mothers of typical children, children with Autism, and children with mental retardation. Autism, 6, 115-130. doi:10.1177/1362361302006001009.

Weiss, J. A., Tint, A., Paquette-Smith, M. \& Lunsky, Y. (2015). Perceived self-efficacy in parents of adolescents and adults with Autism Spectrum Disorder. Autism, 20, 425434. doi:10.1177/1362361315586292.

Woodgate, Ateah \& Secco (2008). Living in a world of our own: The experience of parents who have a child with Autism. Qualitative Health Research, 18, 10751083. doi:10.1177/1049732308320112.

Zimet, G. D., Dahlem, N. W., Zimet, S. G. \& Farley, G, K. (1988). The multidimensional scale of perceived social support. Journal of Personality Assessment, 52, 30-41. doi:10.1207/s15327752jpa5201_2. 


\section{Appendix A}

\section{Ethics approval letter}

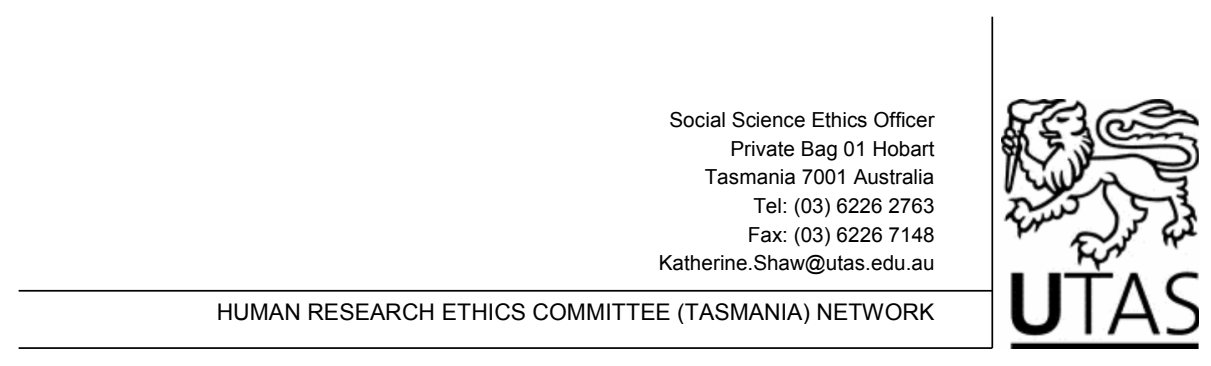

05 May 2017

Dr Kimberley Norris

Division of Psychology

University of Tasmania

Student Researcher: Scarlett Bones

Sent via email

Dear Dr Norris

Re: FULL ETHICS APPLICATION APPROVAL

Ethics Ref: H0016467 - Empirical Validation of a Model Predicting Depression, Anxiety and Stress in the Parents of Children with Autism

We are pleased to advise that the Tasmania Social Sciences Human Research Ethics Committee approved the above project on 05 May 2017.

This approval constitutes ethical clearance by the Tasmania Social Sciences Human Research Ethics Committee. The decision and authority to commence the associated research may be dependent on factors beyond the remit of the ethics review process. For example, your research may need ethics clearance from other organisations or review by your research governance coordinator or Head of Department. It is your responsibility to find out if the approval of other bodies or authorities is required. It is recommended that the proposed research should not commence until you have satisfied these requirements.

Please note that this approval is for four years and is conditional upon receipt of an annual Progress Report. Ethics approval for this project will lapse if a Progress Report is not submitted.

The following conditions apply to this approval. Failure to abide by these conditions may result in suspension or discontinuation of approval.

1. It is the responsibility of the Chief Investigator to ensure that all investigators are aware of the terms of approval, to ensure the project is conducted as approved by the Ethics Committee, and to notify the Committee if any investigators are added to, or cease involvement with, the project. 
2. Complaints: If any complaints are received or ethical issues arise during the course of the project, investigators should advise the Executive Officer of the Ethics Committee on 0362267479 or human.ethics@utas.edu.au.

3. Incidents or adverse effects: Investigators should notify the Ethics Committee immediately of any serious or unexpected adverse effects on participants or unforeseen events affecting the ethical acceptability of the project.

4. Amendments to Project: Modifications to the project must not proceed until approval is obtained from the Ethics Committee. Please submit an Amendment Form (available on our website) to notify the Ethics Committee of the proposed modifications.

5. Annual Report: Continued approval for this project is dependent on the submission of a Progress Report by the anniversary date of your approval. You will be sent a courtesy reminder closer to this date. Failure to submit a Progress Report will mean that ethics approval for this project will lapse.

6. Final Report: A Final Report and a copy of any published material arising from the project, either in full or abstract, must be provided at the end of the project.

Yours sincerely

Katherine Shaw

Executive Officer

Tasmania Social Sciences HREC 


\section{Appendix B}

\section{Participant information sheet}

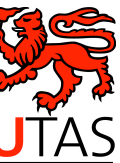

Participant Information Sheet V.01, / /17

Empirical Validation of a Model Predicting Depression, Anxiety and Stress in the Parents of Children with Autism.

\section{Invitation:}

You are invited to participate in a research study examining the factors predicting depression, anxiety and stress in parents of children with Autism Spectrum Disorder (ASD). We are particularly interested in validating a model to predict parental distress. This study is being conducted by student researcher Scarlett Bones, as part of the requirements for the Honours Psychology Program at the University of Tasmania, under the supervision of Dr Kimberley Norris.

Before deciding whether or not you would like to participate please read through the following information so that you have an understanding of the purpose of the study, what it will involve, and any risks and benefits of participating.

\section{What is the purpose of the study?}

The purpose of this study is to examine the factors that predict depression, anxiety and stress in the parents of children with Autism. Furthermore, we aim to provide validation for a model of parental distress.

\section{Why have I been invited to participate?}

You have been asked to participate because you either have a child with Autism aged between 4 years 0 months and 17 years 11 months, or because you have a child without Autism aged between 4 years 0 months and 17 years 11 months.

\section{What will I be asked to do?}

Should you choose to participate in this study, you will be asked to complete a once-off online survey. This survey will contain questions asking about your mental health, your child's symptoms and behaviour, and your social and economic support, as well as some demographic information. Responses will be multiple-choice style.

Your participation is entirely voluntary, and you may discontinue your participation at any time prior to the submission of the questionnaire. As your data is non-identifiable, in that we don't ask for your name or other identifying information, once you have submitted your responses we cannot remove them as there is no way of identifying which data belong to you.

\section{Are there any possible benefits from participation in this study?}

This study gives parents the opportunity to discuss their mental health and the impact that | their child's disorder has on them. This study may therefore provide an opportunity for parents to have their voices heard and discuss issues in a confidential, and anonymous way.

This study may also gives parents the opportunity to contribute to the scientific understanding of Autism beyond the affected child's experience. This study may help explain parental distress, provide evidence for a model of parental distress, and may inform interventions to help prevent/treat parental distress in parents of children with Autism. This could benefit participants in the future, as well as other parents of children with Autism. 


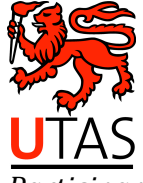

Participant Information Sheet V.01, / /17

It is also possible that you may gain feelings of satisfaction from being able to contribute to a study that could have impacts on many families with a child with Autism.

Additionally, participants in this study may choose to go into the draw to win one of four $\$ 50$ Coles-Myer vouchers as thanks for their participation.

\section{Are there any possible risks from participation in this study?}

This study involves answering questions about your mental health, and your child's disorder and behaviour, which could evoke some anxiety. If you feel any distress during the questionnaire we encourage you to immediately discontinue the study. If you wish to discuss these feelings with someone, you are welcome to contact Dr Kimberley Norris on the phone number or email address at the bottom of this document, or engage with other support services such as lifeline (13 11 14) or Beyond blue (1300 22 4636).

If you have any concerns or questions about the study please feel free to contact Dr Kimberley Norris.

\section{How will my confidentiality be protected?}

As previously mentioned, data will be entirely non-identifiable and will only be accessible to the researchers. Raw data will be destroyed after five years.

7. What if I change my mind during or after the study?

Participation in this study is entirely voluntary and you may withdraw at any point prior to the submission of the questionnaire. As your data is non-identifiable once you have submitted your responses we cannot remove them, as there is no way of identifying which information belongs to you.

8. What will happen to the information when this study is over? The data from this study will be stored for five years on a secure computer. Data will be destroyed after five years.

\section{How will the results of the study be published?}

Preliminary results will be available in December 2017. If you would like a copy of these results you can access these on the University of Tasmania Psychology website located at: http://www.utas.edu.au/health/study/psychology.

If you would like to personally receive a summary of the results, please contact the researchers via the email address provided below.

10. What if I have questions about this study?

If you have questions about the study, feel free to contact either student researcher Scarlett Bones or Chief investigator Dr Kimberley Norris.

This study has been approved by the Tasmanian Social Sciences Human Research Ethics Committee. If you have any concerns or complaints regarding the conduct of this study, 


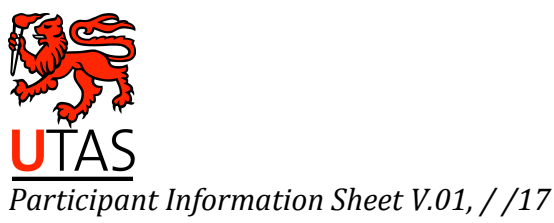

please contact the executive officer of the HREC (Tasmania) Network on +61362666254 or email human.ethics@utas.edu.au. The Executive Officer is the person nominated to receive complains from research participants. Please quote ethics reference number: (Insert ethics reference number)

Thank you for taking the time to consider participation in this study. Completing and submitting the questionnaire on the online survey will be taken as explicit consent to participate in this study.

\section{Contact details:}

- Student Researcher: Scarlett Bones (bonessa@utas.edu.au)

- Chief Investigator: Dr Kimberley Norris (Kimbeley.norris@utas.edu.au or 6226 7199). 
Appendix C

Advertising flyer

\section{Are you a parent? \\ Do you have a child aged between 4 and 17?}

\section{How can you help?}

We want to examine the factors associated with parental distress in parents of children with Autism. Your participation could help us predict parental distress in parents of children with Autism, which could inform treatment interventions.

We are looking for parents of children with Autism AND parents of children without Autism.

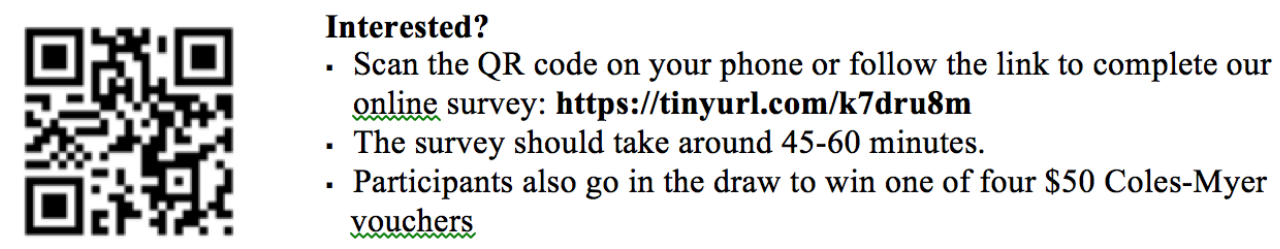




\section{Appendix D}

\section{Demographic questions}

Table D1.

Demographic questions about the parent.

Item
If you are a parent of a child with ASD
whose partner is also completing this survey,
please enter the first two digits of your
home address, and the last two digits of
your child's birth year. The reason we ask
for this is so that we can match your data
with the data from your partner/spouse
while maintaining confidentiality. If your
partner is yet to complete this survey
please ensure that when they do they
insert this number. If your partner/spouse
has already completed this survey please
ensure you insert the same number that
they did.

Do you have a child with a diagnosis of Autism Spectrum Disorder (ASD)?

Response options

Open response.

Yes; No

What is your year of birth?

Open response

What is the highest level of education you have completed?

Including yourself, how may people live in your household?

How many of your children have received a diagnosis of ASD?

What is your marital status?

What are your living arrangements?

Are you currently employed?

What is your total annual income, before taxes?

Some high school (years 7-10); high school (7-10); Some College (years 11-12); College (11-12); Some University; University degree; Post Graduate.

Open response

Open response

Married; De Facto; Separated/Divorced; Widowed; Single; Other

Married couple living together; Married couple living apart; De Facto couple living together; De Facto couple living apart; Single; Other.

Full time; Part time; Not employed.

\$0-19,999; \$20-49,999; \$50-79,999; Over $\$ 80,000$; Not applicable.

\$0-19,999; \$20-49,999; \$50-79,999; \$80- 
taxes?

Have you ever received a diagnosis of, or ever been treated for, any of the following?

Do you have any current diagnosed medical conditions for which you are receiving treatment?

If yes, what medical conditions are you currently seeking treatment for?

\section{0,000; Over $\$ 120,000$}

Anxiety; Depression; Bipolar Disorder; Anorexia; Bulimia; Schizophrenia; Social Phobia; Asperger's Syndrome; Autism; Other mental health disorder (please state).

Yes; No

Open response

Table D2:

Demographic questions about the child.

\begin{tabular}{|c|c|}
\hline Item & Response options \\
\hline How old is your child & Number of years and months. \\
\hline What sex is your child? & Male; Female \\
\hline $\begin{array}{l}\text { Is your child an eldest, middle, youngest or } \\
\text { only child? }\end{array}$ & Eldest; Middle; Youngest; Only \\
\hline What kind of school does your child attend? & $\begin{array}{l}\text { Mainstream school; Special needs day } \\
\text { school; Special needs boarding school; Full- } \\
\text { time home care; Institutional/Hospital care; } \\
\text { Other (please state). }\end{array}$ \\
\hline $\begin{array}{l}\text { When at home, are you the primary carer for } \\
\text { your child? }\end{array}$ & Yes; No \\
\hline What is your relationship with your child? & $\begin{array}{l}\text { Biological Mother; Biological Father; Step } \\
\text { Mother; Step Father; Foster Mother; Foster } \\
\text { Father; Other (please state). }\end{array}$ \\
\hline $\begin{array}{l}\text { Has the child for which you are reporting on } \\
\text { received a diagnosis, now, or in the past, of } \\
\text { any of the following? }\end{array}$ & $\begin{array}{l}\text { Attention Deficit Hyperactivity Disorder; } \\
\text { Oppositional Defiant Disorder; Anxiety; } \\
\text { Depression; Bipolar Disorder; Learning } \\
\text { Disorder; Conduct Disorder; Anorexia; } \\
\text { Bulimia; Schizophrenia; Asperger's } \\
\text { Syndrome; Other (please state). }\end{array}$ \\
\hline
\end{tabular}




\section{Appendix E}

Economic support questions

Item

Response options

You have a special person who is willing and Strongly Disagree; Disagree; Neither Agree able to help you financially

Nor Disagree; Agree; Strongly Agree

You have some family or friends who are Strongly Disagree; Disagree; Neither Agree willing and able to help you financially.

Nor Disagree; Agree; Strongly Agree 
Appendix F

Summary of intercorrelations between model indicators.

\begin{tabular}{lcccccccccc}
\hline Indicator & 1 & 2 & 3 & 4 & 5 & 6 & 7 & 8 & 9 & 10 \\
\hline 1. SoSup & - & - & - & - & - & - & - & - & - & - \\
2. EcSup & .53 & - & - & - & - & - & - & - & - & - \\
3. Dep & -.56 & -.42 & - & - & - & - & - & - & - & - \\
4. Anx & -.46 & -.32 & .64 & - & - & - & - & - & - & - \\
5. Stress & -.48 & -.28 & .70 & .77 & - & - & - & - & - & - \\
6. Com & -.30 & -.24 & .33 & .28 & .32 & - & - & - & - & - \\
7. SocIn & -.44 & -.31 & .42 & .39 & .42 & .69 & - & - & - & - \\
8. ConPr & -.38 & -.21 & .25 & .26 & .31 & .22 & .30 & - & - & - \\
9. Agg & -.30 & -.20 & .33 & .28 & .30 & .21 & .36 & .66 & - & - \\
10. LimS & -.35 & -.28 & .30 & .26 & .32 & .32 & .44 & .55 & .44 & - \\
11. Ploc & -.47 & -.33 & .42 & .36 & .44 & .30 & .44 & .51 & .51 & .64 \\
\hline
\end{tabular}

Note. SocSup: Social Support; EcSup: Economic Support; Dep: Depression; Anx: Anxiety;

Com: Communication Skills; SocIn: Social Interactions; ConPr: Conduct Problems; Agg:

Aggressive Behaviour; Lims: Perceived Limit Setting Ability; Ploc: Parental Locus of Control. 